\title{
Estimation of $\mathrm{ET}_{\mathrm{o}}$ with Hargreaves-Samani and FAO-PM temperature methods for a wide range of climates in Iran
}

\author{
Tayeb Raziei ${ }^{a, b, *}$, Luis S. Pereira ${ }^{b}$ \\ a Soil Conservation and Watershed Management Research Institute (SCWMRI), Tehran, Iran \\ ${ }^{\mathrm{b}}$ CEER - Biosystems Engineering, Institute of Agronomy, Technical University of Lisbon, Portugal
}

\section{A R T I C L E I N F O}

\section{Article history:}

Received 24 September 2012

Accepted 21 December 2012

Available online 14 February 2013

\section{Keywords:}

Reference evapotranspiration

Dew point temperature

Radiation adjustment coefficient

Temperature adjustment

Humid vs. arid regions

Wind speed

Spatial variability

\begin{abstract}
A B S T R A C T
Monthly data records of 40 Iranian stations distributed over the country, for the period 1971-2005, were utilized for estimation of reference evapotranspiration ( $\left.\mathrm{ET}_{\mathrm{o}}\right)$ using Penman-Monteith (PM-ET $)_{0}$, Hargreaves-Samani (HS) and FAO-PM temperature (PMT) methods. To estimate $\mathrm{ET}_{0}$ with HS and PMT methods, appropriate $k_{\mathrm{Rs}}$, an empirical radiation adjustment coefficient, were considered for each station, whereas $T_{\min }$ was adjusted for estimation of $T_{\text {dew }}$ and used only for PMT computation. It was found that the appropriate $k_{\mathrm{Rs}}$ for both HS and PMT methods are identical for a given station and it is generally smaller in sub-humid and humid than in semi-arid to hyper-arid climates. The performance of the PMT was further improved in both arid and humid climates when $T_{\min }$ was adjusted. The result suggested that the HS and PMT methods appropriately predict $\mathrm{ET}_{0}$ for all climatic regions of Iran if the appropriate $k_{\mathrm{Rs}}$ was utilized. However, the considered methods showed weak performances for some stations in arid and hyper-arid climates of eastern and southern Iran owing to the effect of extreme and variable wind speed inherent in the PM-ETo . Thus, the role played by wind speed in $\mathrm{ET}_{\mathrm{o}}$ estimation was examined; the result indicated that the existence of extreme winds, and also the time variability of wind speed,

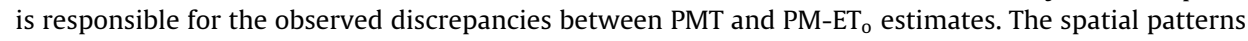
of $\mathrm{ET}_{0}$ computed with HS and PMT methods found to be identical and resemble to that of PM-ET ${ }_{0}$, all showing a gradual increasing from north to south, with the lowest $\mathrm{ET}_{\mathrm{o}}$ values observed over northern humid and sub-humid climates of Iran and larger $\mathrm{ET}_{0}$ for arid and hyper-arid climates in the southern and eastern country. Results indicated that the HS and PMT methods are appropriate alternatives for estimation of $\mathrm{ET}_{\mathrm{o}}$ for all climatic regions of Iran.
\end{abstract}

(ㄷ) 2013 Elsevier B.V. All rights reserved.

\section{Introduction}

Adequate estimation of reference evapotranspiration $\left(\mathrm{ET}_{0}\right)$ is of paramount importance in agricultural and hydrological studies, water resources management and watershed management. In particular, it is required for estimation of crop water requirements, supporting irrigation scheduling, drought management and climate change studies. The methodologies of $\mathrm{ET}_{\mathrm{o}}$ estimation redefined by Food and Agricultural Organization of United Nations (FAO) were successfully applied at different time scales in various climatic regions of the world (Allen et al., 1998, 2006; Smith,

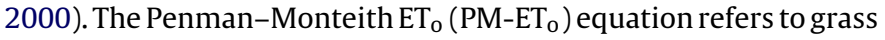
as reference crop and requires solar radiation data or sunshine

\footnotetext{
* Corresponding author at: Soil Conservation and Watershed Management Research Institute (SCWMRI), Tehran, Iran, and CEER - Biosystems Engineering, Institute of Agronomy, Technical University of Lisbon, Portugal. Tel.: +351213653480.

E-mail addresses: tayebrazi@yahoo.com (T. Raziei), lspereira@isa.utl.pt (L.S. Pereira).
}

duration for estimating net radiation $\left(R_{\mathrm{n}}\right)$, maximum and minimum temperature ( $T_{\max }$ and $T_{\min }$, respectively), psycrometric or relative humidity data for estimating the vapour pressure deficit (VPD) and wind speed $(U)$ When formulating the $P M-E_{0}$ equation advection effects were not considered (Allen et al., 1998; Pereira et al., 1999). Advection impacts on crop evapotranspiration must be considered through the crop coefficients and not $\mathrm{ET}_{\mathrm{o}}$ (Allen et al., 1998). However, when searching for $\mathrm{ET}_{\mathrm{o}}$ data estimation under advective conditions, Berengena and Gavilán (2005) found that daily $\mathrm{ET}_{0}$ estimates using the PM-ET $\mathrm{P}_{\mathrm{o}}$ equation matched well the lysimeter observations of grass ET. Good results are reported for daily computations using hourly data in locations having advective influences (Allen et al., 2006).

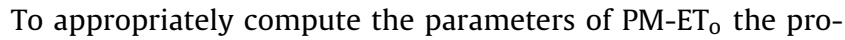
cedures proposed by Allen et al. (1998) should be followed. Alternative procedures have been tested by Nandagiri and Kovoor (2005), who have shown the need for strict adherence to the recommended parameter computation procedures, especially for estimating vapour pressure deficit and net radiation parameters. Gavilán et al. (2007) reported that the methods proposed by Allen et al. (1998) for estimating $R_{\mathrm{n}}$ and $G$ are appropriate for 
estimation of $\mathrm{ET}_{\mathrm{o}}$ for both daily and hourly time scales. Gong et al.

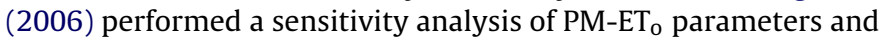
pointed to the very high influence of solar radiation and relative

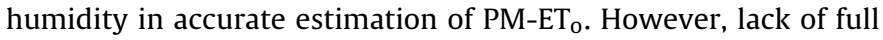
weather datasets in many parts of the world, particularly in remote

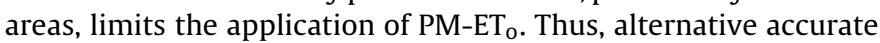
approaches requiring limited data are needed, which has led to a huge number of related studies focusing various climates.

According to Allen et al. (1998), and basing upon former studies to compare the performance of ET temperature methods, mainly the study by Jensen et al. (1990), when full weather data are lacking $\mathrm{ET}_{\mathrm{O}}$ can be estimated either using the empirical Hargreaves-Samani (HS) equation (Hargreaves and Samani, 1985), or empirically estimating $R_{\mathrm{n}}$, VPD and $\mathrm{U}$ for using in the PM-ET $\mathrm{O}_{\mathrm{o}}$ equation, including through using data from neighbour weather stations (Allen, 1997). Various ET temperature methods were then excluded - and consequently are not considered in this study -, particularly the ET climatic equation of Thornthwaite (1948), that largely underesti-

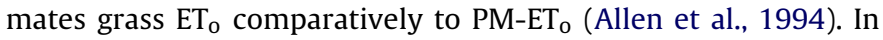
both aforementioned methods the minimum set of data required consists of $T_{\max }$ and $T_{\min }$. The latter approach for using the PM-ET with only $T_{\max }$ and $T_{\min }$ is called herein as PM temperature (PMT) method and is also referred in literature as reduced set PM method (e.g., Martinez and Thepadia, 2010). Both the HS and PMT methods have received a continuous attention from research contrarily to the use of neighbour weather data; however, a recent methodology based on principal component analysis to estimate $\mathrm{ET}_{\mathrm{o}}$ when no local climatic inputs are available (Martí and Zarzo, 2012) may provide new developments in this domain.

The $\mathrm{ET}_{\mathrm{o}}$ estimated by the $\mathrm{HS}$ equation have been successfully compared with the $\mathrm{ET}_{0}$ computed with the $\mathrm{PM}-\mathrm{ET}_{\mathrm{o}}$ equation using full datasets, or with grass lysimeter data, indicating that the HS method performs well in most climatic regions, with the exception of humid area where it tends to overestimate $\mathrm{ET}_{\mathrm{o}}$ (Nandagiri and Kovoor, 2006; Trajkovic and Kolakovic, 2009; Martinez and Thepadia, 2010; Tabari, 2010). Since the HS method was empirically developed based on data from arid to sub-humid environments, it may not fit well to conditions far different from those considered for its calibration as it is the case for humid climates. Temesgen et al. (2005) also stated that the HS method underestimates $\mathrm{ET}_{0}$ for dry and windy locations due to not considering a wind factor and concluded that it is more accurate when applied for 5 or 7day averages than for daily time scales. However, despite a quite good performance of the HS equation in most applications, particularly when it is used for irrigation scheduling purposes, many authors attempted to recalibrate the HS coefficients or parameters in order to improve its performance (e.g., Droogers and Allen, 2002; Trajkovic, 2007; Fooladmand et al., 2008), or to modify the equation itself (Diodato and Bellocchi, 2007). This resulted in a large number of versions of the HS equation, that relates with the purpose of many researchers to find locally calibrated versions of the HS equation.

Based on a careful analysis of the history and applications of the HS equation, Hargreaves and Allen (2003) concluded that recalibrating the exponents and coefficients of the HS equation only increased the complexity of the equation. The HS method is usually preferred with respective to other more complicated equations since it is reasonably adequate and requires only maximum and minimum air temperatures (Hargreaves and Allen, 2003). This is very important in regions where solar radiation, air humidity, and wind speed data are lacking or are of low or questionable quality, while the maximum and minimum air temperatures are available in most of agro-climatic and weather stations since air temperature can be measured with less errors and by less trained individuals than the other required climate variables used in combination equations.
The accuracy of the PMT equation has been assessed by several authors through comparing its results with those of the PM-ET or other ET equations, HS included. Popova et al. (2006) found more accurate results for PMT than for HS, which tended to overestimate $\mathrm{ET}_{\mathrm{o}}$ in the Trace plain area of southern Bulgaria. For Pyrenees, López-Moreno et al. (2009) obtained better results with PMT when compared with HS method. Similarly, Jabloun and Sahli (2008) found better estimates for PMT than for HS in Northern and Central Tunisia. An application of PMT for Northern China, characterized with monsoon climate, also have shown that the PMT

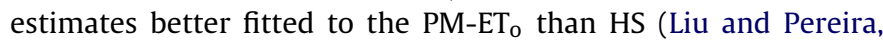
2001; Pereira et al., 2003). Application of PMT to different climates of South Africa showed to be superior to HS and that better results were obtained when applied to 5-day rather than daily time scales (Annandale et al., 2002). The estimated $\mathrm{ET}_{0}$ computed by PMT and HS method for Serbia suggested that PMT fitted better PM-ET $\mathrm{P}_{0}$ than HS (Trajkovic, 2005). Differently, it was found that the HS produced smaller overestimation errors than PMT in a humid climate (Martinez and Thepadia, 2010). Kra (2010) applied a modified PMT method in West Africa, while Cai et al. (2007) used a modified PMT approach for estimating $\mathrm{ET}_{\mathrm{o}}$ with daily forecast messages; lately, the PMT was adapted for using daily forecasted weather data for irrigation scheduling purposes (Cai et al., 2009). Paredes and Rodrigues (2010) found small errors with PMT relative to HS, thus adopting it to estimate $\mathrm{ET}_{0}$ in Portugal for irrigation scheduling purposes; they found that estimation errors were larger in humid locations comparative to dryer ones. Gocic and Trajkovic (2010) proposed a software to estimate $\mathrm{ET}_{\mathrm{o}}$ for minimizing computation errors using the PMT or an adjusted HS equation when weather data are missing. However, current literature show that there are no attempts to calibrate the radiation adjustment coefficient $k_{\mathrm{Rs}}$ used to estimate solar radiation from the temperature difference in PMT and, non-explicitly, in HS (Hargreaves and Allen, 2003; Samani, 2000, 2004). This calibration is therefore a line to be explored in this study. Moreover, literature looks to be controversial when comparing HS and PMT results as was identified by Todorovic et al. (2013).

Due to the complex orography and wide latitudinal extent, Iran contains diverse climates ranging from very humid in the Caspian Sea region to arid and hyper arid in the central, southern and eastern Iran. In this vast area, the stations recording the climate variables needed for estimation of $\mathrm{PM}-\mathrm{ET}_{\mathrm{o}}$ are very sparse and in many cases have incomplete records, particularly in the centralsouthern country where the Iranian deserts are situated. Therefore, to have a reliable estimation of $\mathrm{ET}_{\mathrm{o}}$ at a fine spatial resolution over the country, it is important to use accurate methods requiring limited weather data that can be available in a dense network through the country as it is the case for temperature. To our best knowledge, Dinpashoh (2006) is the only author that has estimated

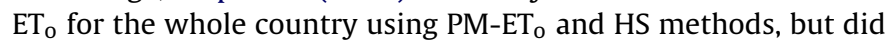
not tested the possible advantages in using calibrated values for the radiation adjustment coefficient or temperature adjustment for dew point temperature estimation for the PMT method as proposed by Allen (1996). The adequateness of using PM-ET $_{0}$ in Iran is also demonstrated by Dinpashoh et al. (2011) through a trend analysis

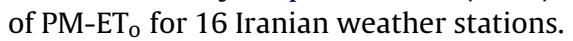

Several authors have also assessed the application of other methods requiring minimum data for estimation of $\mathrm{ET}_{\mathrm{o}}$ in some parts of Iran rather than for the whole country (Fooladmand and Haghighat, 2007; Ahmadi and Fooladmand, 2008; Rahimikhoob, 2010; Tabari et al., 2011a; Tabari and Aghajanloo, 2012). However, a calibration of the radiation adjustment coefficient was not attempted in any of the later referred studies and the PMT and HS methods were not compared. Therefore, the objective of the present study is to evaluate the potential and accuracy of the PMT and HS methods for estimation of $\mathrm{ET}_{\mathrm{o}}$ in different climatic regions of Iran 

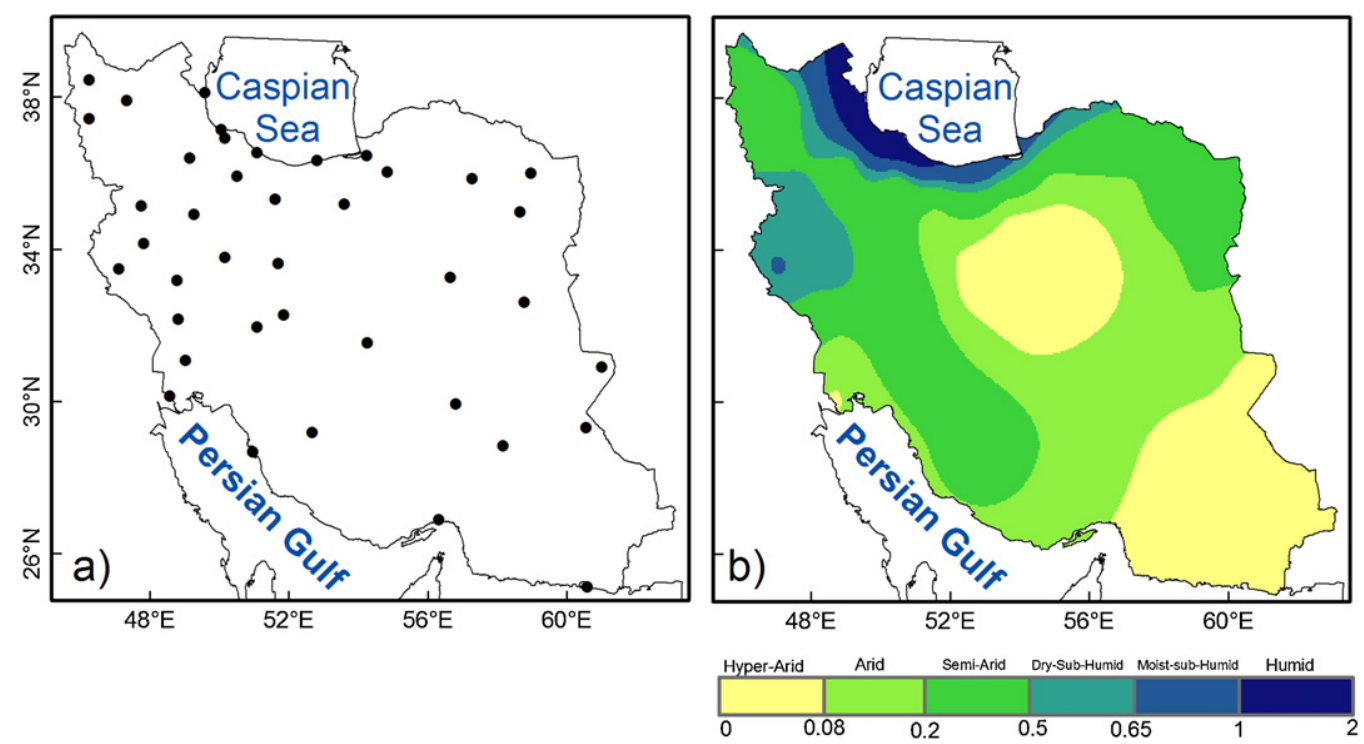

Fig. 1. Spatial distribution of (a) the utilized weather stations and (b) the aridity index over Iran.

and to refine the methodologies for better adapting both the PMT and HS methods to the existing environmental conditions. Thus, it is aimed to compare the PMT and HS methods, to find the best values for the radiation adjustment coefficient to be used with both methods, to assess the advantage in correcting the minimum temperature when estimating VPD, and to assess the impacts of high wind speed in arid zones. These objectives are set to support a wide range of irrigation management and water resources applications, particularly relative to droughts, for use in regions where weather data are missing, are incomplete or are of questionable quality.

\section{Materials and methods}

\subsection{Data}

The data used for this study are monthly averages of maximum and minimum temperature $\left({ }^{\circ} \mathrm{C}\right)$, relative humidity (\%), sunshine duration $(\mathrm{h})$ and wind speed $\left(\mathrm{m} \mathrm{s}^{-1}\right)$ relative to 40 Iranian synoptic stations distributed over the country as depicted in Fig. 1a; the associated coordinates are shown in Table 1 . The majority of the selected stations have the longest and nearly complete data records for the period 1971-2005, particularly considering sunshine, relative humidity and wind speed data. The selected stations are first order synoptic stations that passed careful quality control by the Iranian meteorological organization and are quite regularly distributed through the country (Fig. 1a). However, the time series of the considered variables were further investigated for possible non-homogeneities by comparing the time series of a given station with those of neighbouring stations. The result proved that all the variables were homogeneous, with the exception of wind speed records at Tabass, Bam, Semnan, Kashan, Khoramabad, Dezful and Chabahar stations, which exhibited extreme step changes and nonhomogeneity. Therefore, the wind datasets at these 7 stations were corrected through establishing linear regression between the considered station data and those of neighbouring stations as proposed by Allen et al. (1998).

The considered stations for the present study encompass several representative stations for each climatic sub-region of Iran, defined herein on the basis of the global aridity index (UNEP, 1997) adopted by the United-Nations Convention to Combat Desertification. The

Table 1

Coordinates and the aridity index (AI) of the utilized weather stations.

\begin{tabular}{|c|c|c|c|c|c|c|c|c|c|}
\hline Stations & Lat. & Lon. & Alt & AI index & Stations & Lat. & Lonn. & Alt & AI index \\
\hline Astara & 38.4 & 48.9 & -18.0 & 1.67 & Shiraz & 29.5 & 52.6 & 1484.0 & 0.35 \\
\hline Anzali & 37.5 & 49.5 & -26.2 & 2.09 & Tabriz & 38.1 & 46.3 & 1361.0 & 0.35 \\
\hline Rasht & 37.3 & 49.6 & -6.9 & 1.64 & Torbat & 35.3 & 59.2 & 1450.8 & 0.35 \\
\hline Ramsar & 36.9 & 50.7 & -20.0 & 1.45 & Zanjan & 36.7 & 48.5 & 1663.0 & 0.44 \\
\hline Babolsar & 36.7 & 52.7 & -21.0 & 1.04 & Abadan & 30.4 & 48.3 & 6.6 & 0.07 \\
\hline Ilam & 33.6 & 46.4 & 1337.0 & 0.68 & Ahwaz & 31.3 & 48.7 & 22.5 & 0.10 \\
\hline Gorgan & 36.9 & 54.3 & 13.3 & 0.61 & Bam & 29.1 & 58.4 & 1066.9 & 0.04 \\
\hline Kermanshah & 34.4 & 47.2 & 1318.6 & 0.56 & Bandar Abas & 27.2 & 56.4 & 9.8 & 0.09 \\
\hline Khoramabad & 33.4 & 48.3 & 1147.8 & 0.55 & Birjand & 32.9 & 59.2 & 1491.0 & 0.20 \\
\hline Sanandaj & 35.3 & 47.0 & 1373.4 & 0.59 & Bushehr & 29.0 & 50.8 & 19.6 & 0.15 \\
\hline Arak & 34.1 & 49.8 & 1708.0 & 0.41 & Chabahar & 25.3 & 60.6 & 8.0 & 0.07 \\
\hline Dezful & 32.4 & 48.4 & 143.0 & 0.25 & Isfahan & 32.6 & 51.7 & 1550.4 & 0.14 \\
\hline Ghazvin & 36.3 & 50.1 & 1279.2 & 0.41 & Kashan & 34.0 & 51.5 & 982.3 & 0.12 \\
\hline Hamedan & 35.2 & 48.7 & 1679.7 & 0.48 & Kerman & 30.3 & 57.0 & 1753.8 & 0.17 \\
\hline Khoy & 38.6 & 45.0 & 1103.0 & 0.41 & Sabzevar & 36.2 & 57.7 & 977.6 & 0.20 \\
\hline Mashhad & 36.3 & 59.6 & 999.2 & 0.33 & Semnan & 35.6 & 53.6 & 1130.8 & 0.14 \\
\hline Mehrabad & 35.7 & 51.3 & 1190.8 & 0.24 & Tabass & 33.6 & 56.9 & 711.0 & 0.06 \\
\hline Urmia & 37.5 & 45.1 & 1315.9 & 0.48 & Yazd & 31.9 & 54.3 & 1237.2 & 0.05 \\
\hline Shahrekord & 32.3 & 50.9 & 2048.9 & 0.48 & Zabol & 31.0 & 61.5 & 489.2 & 0.04 \\
\hline Shahroud & 36.4 & 55.0 & 1345.3 & 0.20 & Zahedan & 29.5 & 60.9 & 1370.0 & 0.08 \\
\hline
\end{tabular}


UNEP aridity index, which is also adopted by FAO and used worldwide consists of the ratio of mean annual precipitation $(P)$ to mean annual potential evapotranspiration computed with the Thornthwaite method (Thornthwaite, 1948). The computed aridity index for the considered stations are also presented in Table 1 to climatically characterize the used stations, while the spatial distribution of the index over the country is depicted in Fig. 1b. The map of aridity index points to the humid and sub-humid climates over coastal areas of the Caspian Sea in northern Iran. Dry-sub-humid climate features occur in the highest parts of the Alborz mountain chain in the north, thus acting as a transitional band, isolating humid and sub-humid climates of the coastal areas of the Caspian Sea from the semi-arid areas of interior Iran (Fig. 1b). The dry-sub-humid climate also characterizes a remarkable part of western Iran due to its relatively high annual precipitation accompanied with cold winters and moderate summers. Semi-arid climates refer to the mountainous areas of western, northern and north-eastern Iran, whereas arid and hyper-arid climates dominate central, southern and eastern Iran (Fig. 1b). The climate sub-regions of Iran produced herein based on the spatial variability of the aridity index, though methodologically and conceptually different, are in relatively good agreement with the results of the precipitation based regionalization studies for Iran in illustrating the main structure of the Iranian climate (e.g., Dinpashoh et al., 2004; Raziei et al., 2008).

\subsection{Methods to estimate $E T_{0}$}

The $\mathrm{PM}-\mathrm{ET}_{\mathrm{O}}$ equation is aimed to define the grass reference evapotranspiration, i.e., the rate of evapotranspiration from a hypothetical crop with an assumed fixed height $(12 \mathrm{~cm})$, surface resistance $\left(70 \mathrm{~s} \mathrm{~m}^{-1}\right)$ and albedo $(0.23)$, approximately resembling the evapotranspiration from an extensive surface of a disease-free green grass cover of uniform height, actively growing, completely shading the ground, and with adequate water and nutrient supply (Allen et al., 1998). The PM-ET ${ }_{0}$ equation for calculation of daily $\mathrm{ET}_{0}$ takes the form:

$\mathrm{ET}_{\mathrm{o}}=\frac{0.408 \Delta\left(R_{\mathrm{n}}-G\right)+\gamma(900 /(T+273)) u_{2}\left(e_{\mathrm{s}}-e_{\mathrm{a}}\right)}{\Delta+\gamma\left(1+0.34 u_{2}\right)}$

where $\mathrm{ET}_{0}$ is the grass reference evapotranspiration $\left(\mathrm{mmday}^{-1}\right)$, $R_{\mathrm{n}}$ is the net radiation at the crop surface (MJ m${ }^{-2}$ day $^{-1}$ ), $G$ is soil heat flux density $\left(\mathrm{MJ} \mathrm{m}^{-2}\right.$ day $\left.^{-1}\right), T$ is mean daily air temperature at $2 \mathrm{~m}$ height $\left({ }^{\circ} \mathrm{C}\right), u_{2}$ is wind speed at $2 \mathrm{~m}$ height $\left(\mathrm{m} \mathrm{s}^{-1}\right), e_{\mathrm{s}}$ is saturation vapor pressure $(\mathrm{kPa}), e_{\mathrm{a}}$ is actual vapor pressure $(\mathrm{kPa}), e_{\mathrm{s}}-e_{\mathrm{a}}$ is vapor pressure deficit ( $\mathrm{kPa}), \Delta$ is slope of the vapor pressure curve $\left(\mathrm{kPa}^{\circ} \mathrm{C}^{-1}\right)$, and $\gamma$ is psychometric constant $\left(\mathrm{kPa}{ }^{\circ} \mathrm{C}^{-1}\right)$. This equation uses standard meteorological records of solar radiation or sunshine duration, minimum and maximum air temperature, air humidity and wind speed. To ensure the integrity of computations, the weather measurements should be made at $2 \mathrm{~m}$ (or converted to that height) above an extensive surface of green grass, shading the ground and not short of water. The parameters of Eq. (1) can be estimated from the observed climatic variables following the standard methods proposed by Allen et al. (1998), whereas the missing climatic data can be estimated empirically as follows.

$R_{\mathrm{n}}$ is computed as the algebraic sum of the net short and long wave radiation ( $R_{\mathrm{ns}}$ and $R_{\mathrm{nl}}$, respectively). $R_{\mathrm{ns}}$, results from the balance between incoming and reflected solar radiation $\left(R_{\mathrm{S}}\right)$ adopting an albedo of 0.23 , and $R_{\mathrm{nl}}$ results from the balance between the down-coming and the outgoing long wave radiation emitted by the vegetation and the soil. Computations were performed as proposed by Allen et al. (1998). When $R_{\mathrm{S}}$ is not measured, it can be estimated from the observed duration of sunshine hours with the Angström (1924) equation:

$R_{\mathrm{s}}=\left(a_{\mathrm{s}}+b_{\mathrm{s}} \frac{n}{N}\right) R_{\mathrm{a}}$

where $R_{\mathrm{S}}$ is solar or shortwave radiation $\left(\mathrm{MJ} \mathrm{m}^{-2} \mathrm{day}^{-1}\right), n$ is actual sunshine duration (h), $N$ is maximum possible sunshine duration (h), $n / N$ is relative sunshine duration, $R_{\mathrm{a}}$ is extraterrestrial radiation $\left(\mathrm{MJ} \mathrm{m}^{-2} \mathrm{day}^{-1}\right), a_{\mathrm{s}}$ is the coefficient expressing the fraction of extraterrestrial radiation reaching the earth on overcast days ( $n=0)$, and $a_{\mathrm{s}}+b_{\mathrm{s}}$ is the fraction of extraterrestrial radiation reaching the earth on clear sky days $(n=N)$. $R_{\mathrm{a}}$ and $N$ are computed for any given day as a function of the latitude of the site (Allen et al., 1998). When using monthly time steps $R_{\mathrm{a}}$ and $N$ are computed for the central day of the month. The values $a_{\mathrm{s}}=0.25$ and $b_{\mathrm{s}}=0.50$ are recommended when these fractions are not locally calibrated using a set of good quality data on both $n / N$ and $R_{\mathrm{s}}$.

When radiation and sunshine duration measurements are not available, the PMT method uses the Hargreaves radiation equation (Hargreaves and Samani, 1982) for the estimation of solar radiation $\left(R_{\mathrm{S}}\right)$ in alternative to Eq. (2):

$R_{\mathrm{S}}=k_{R_{\mathrm{s}}} \sqrt{\left(T_{\max }-T_{\min }\right)} R_{\mathrm{a}}$

where $k_{\mathrm{Rs}}$ is the empirical radiation adjustment coefficient $\left({ }^{\circ} \mathrm{C}^{-0.5}\right)$. For 'interior' locations, where land mass dominates and air masses are not strongly influenced by a large water body, Allen (1997) and Allen et al. (1998) proposed $k_{\mathrm{Rs}} \cong 0.16$ for 'interior' areas and $k_{\mathrm{Rs}} \cong 0.19$ for 'coastal' locations. These values are the same as those proposed previously by Hargreaves (1994). Inherent to its empirical nature, there is some uncertainty relatively to this coefficient (Samani, 2004). Popova et al. (2006) reported that for temperate climate $k_{\mathrm{Rs}}$ values change little. Differently, for a wide range of climates as in the Mediterranean countries a large variation was observed (Todorovic et al., 2013).

Vapour pressure deficit (VPD) is computed as the difference between the saturation vapour pressure $\left(e_{s}\right)$ and the actual vapour pressure $\left(e_{\mathrm{a}}\right) \cdot e_{\mathrm{s}}$ is computed as the average of the saturation vapour pressure at $T_{\max }$ and $T_{\min }$. Various approximations may be used to estimate $e_{\mathrm{a}}$ depending upon available data. When only mean daily relative humidity $\left(\mathrm{RH}_{\text {mean }}\right)$ data are available, as for the complete datasets used in this study, $e_{\mathrm{a}}$ is computed as (Allen et al., 1998):

$e_{\mathrm{a}}=\frac{\mathrm{RH}_{\text {mean }}}{50 /\left(e^{\mathrm{o}}\left(T_{\min }\right)\right)+50 /\left(e^{o}\left(T_{\max }\right)\right)}$

In the absence of humidity data, $e_{\mathrm{a}}$ may be obtained by assuming that the dew point temperature, $T_{\mathrm{dew}}$, is close to the daily minimum temperature, $T_{\min }$. Then, if the weather station can be considered a reference site where $T_{\mathrm{dew}}=T_{\min }, e_{\mathrm{a}}$ is calculated by

$e_{\mathrm{a}}=e^{\mathrm{o}}\left(T_{\min }\right)=0.611 \exp \left[\frac{17.27 T_{\min }}{T_{\min }+237.3}\right]$

The HS method (Hargreaves and Samani, 1985) requires only observed $T_{\min }$ and $T_{\max }$ for the estimation of $\mathrm{ET}_{\mathrm{o}}\left(\mathrm{mm} \mathrm{day}^{-1}\right)$, which is given as:

$\mathrm{ET}_{\mathrm{o}}=0.0135 k_{R_{\mathrm{s}}} \frac{R_{\mathrm{a}}}{\lambda} \sqrt{\left(T_{\max }-T_{\min }\right)}(T+17.8)$

where $R_{\mathrm{a}}$ is the extraterrestrial radiation as defined earlier, and $\lambda$ is the latent heat of vaporization $\left(\mathrm{MJ} \mathrm{kg}^{-1}\right)$ for the mean air temperature $T\left({ }^{\circ} \mathrm{C}\right)$, that is commonly assumed equal to $2.45 \mathrm{MJ} \mathrm{kg}^{-1} .0 .0135$ is a factor for conversion from American to the International system of units and $k_{\mathrm{Rs}}$ is the radiation adjustment coefficient defined in Eq. (3). In the common version of HS equation the value $k_{\mathrm{Rs}} \cong 0.17$ is used (Samani, 2004). 


\subsection{Temperature adjustment for estimating $P M T-E T_{o}$}

Data quality assessment and data correction for non-reference weather sites, i.e., where aridity is dominant, were proposed by Allen et al. (1998) as a pre-condition for accuracy of PM-ET ${ }_{0}$ calculations. In fact, the PM-ET ${ }_{0}$ definition implies the consideration of an actively growing grass crop completely shading the ground and not short of water. However, many, if not the majority of the weather data around the globe are reported from non-reference sites, and their use to estimate $\mathrm{ET}_{0}$ may cause less accuracy of estimates. If data quality is essential for any kind of evapotranspiration studies (Allen et al., 2011), requirements for aridity corrections relate

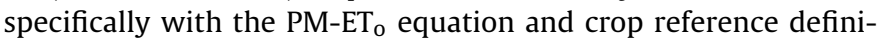
tion. That correction was analyzed by Allen (1996), Jensen et al. (1997) and Temesgen et al. (1999), and refers to correct temperature by 2 or 3 degrees to approach $T_{\min }$ of $T_{\text {dew }}$ when the site temperature is higher than that expected for a reference site while air humidity is lower. Temesgen et al. (1999) have shown small effects of this correction on $\mathrm{ET}_{\mathrm{o}}$ estimated with the HS equation because this equation does not explicitly use dew point temperature and wind speed, both of which are affected by site aridity. These authors also considered that where the aridity of the site increases it mixes up the top and bottom layers of the atmosphere. The mixing of different layers in turn reduces the temperature range $\left(\mathrm{TR}=T_{\max }-T_{\min }\right.$ ) by decreasing $T_{\max }$ during daytime and by increasing $T_{\min }$ during night-time, thereby keeping the increase in estimated $\mathrm{ET}_{\mathrm{o}}$ lower than that for $\mathrm{PM}^{\mathrm{E}} \mathrm{ET}_{\mathrm{o}}$ as aridity increases. The humidity term is only implicitly contained in the TR term of the Hargreaves equation. The analysis by Hargreaves and Allen (2003) agrees with the hypothesis of Temesgen et al. (1999), thus not considering the need for site aridity correction when the HS equation is used.

The PMT method uses as input only measured minimum and maximum air temperature for the estimation of $\mathrm{ET}_{0}$ by the PM$\mathrm{ET}_{\mathrm{o}}$ equation (Eq. (1)), whereas wind speed is fixed to $2 \mathrm{~m} \mathrm{~s}^{-1}$ (the average value of 2000 weather stations over the globe) and solar radiation and actual vapour pressure are estimated by Eqs. (3) and (5), respectively (Allen et al., 1998; Popova et al., 2006).

As discussed before, when applying the PMT method there is a need for adjustment of temperature used for the estimation of actual vapour pressure. $T_{\min }$ might be greater than $T_{\text {dew }}$ in a non-reference weather station, as for a station located inside a town or having dry or bare ground. Then, the estimated value for $T_{\text {dew }}$ from $T_{\text {min }}$ may require correction (Allen, 1996; Allen et al., 1998; Temesgen et al., 1999), which is expected to be higher in more arid climates. Considering the climate zones defined in Table 2 and illustrated in Fig. 1b, the corrections of $T_{\text {dew }}$ are proposed for all months where $P / \mathrm{ET}_{\mathrm{o}}<0.65$ (Todorovic et al., 2013).

Differently, in humid climate where commonly air humidity is high and temperatures are relatively low, very likely $T_{\text {dew }}$ is higher or much higher than $T_{\min }$. Therefore, for the humid stations situated in the Caspian Sea region, considering the relations for $T_{\mathrm{dew}}$ in moist air proposed by Lawrence (2005), and following the good results

Table 2

Correction of $T_{\mathrm{dew}}$ estimates from $T_{\min }$ for estimation of actual vapor pressure.

\begin{tabular}{lcl}
\hline Climate zones & Annual $P / \mathrm{ET}_{\mathrm{o}}$ & Corrected $T_{\mathrm{dew}}\left({ }^{\circ} \mathrm{C}\right)$ \\
\hline Hyper-arid & $<0.08$ & $T_{\mathrm{dew}}=T_{\min }-4$ \\
Arid & $0.08-0.20$ & $T_{\mathrm{dew}}=T_{\min }-2$ \\
Semi-arid & $0.20-0.50$ & $T_{\mathrm{dew}}=T_{\min }-1$ \\
Dry sub-humid & $0.50-0.65$ & $T_{\mathrm{dew}}=T_{\min }-1$ \\
Moist sub-humid & $0.65-1.0$ & No correction for aridity \\
Humid & $>1.0$ & No correction for aridity \\
\hline
\end{tabular}

previously obtained for the Mediterranean area (Todorovic et al., 2013), $T_{\text {dew }}$ was estimated as follows:

$T_{\mathrm{dew}}=\left(\frac{T_{\min }+T_{\max }}{2}\right)-a_{\mathrm{d}}$

with $a_{\mathrm{d}}=2{ }^{\circ} \mathrm{C}$ for the months when $0.8<P / \mathrm{ET}_{\mathrm{o}}<1.0$ and $a_{\mathrm{d}}=1{ }^{\circ} \mathrm{C}$ if $P / \mathrm{ET}_{\mathrm{O}}>1.0$.

\subsection{Evaluation procedure}

A trial and error procedure was applied to all datasets to find the best values for $k_{\text {Rs }}$ since the relations proposed by Samani (2000, 2004) did not show to be appropriate. PMT computations were performed with temperature correction for aridity effects (Table 2) or for humidity impacts on $T_{\text {dew }}$ as described in Section 2.3. The results of $\mathrm{ET}_{\mathrm{o}}$ estimated by PMT and HS methods using limited weather

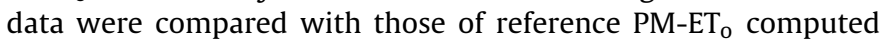
using full datasets. To assess the performance of HS and PMT meth-

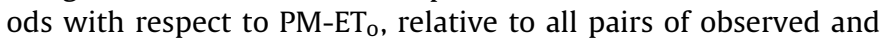
predicted values for each station, in addition to a linear regression forced to the origin, several statistical indicators were also used. These indicators are explained below and their equations are given in literature, e.g., the comparative study of $\mathrm{ET}_{\mathrm{o}}$ models by Todorovic et al. (2013).

If the coefficient of regression $b$ is close to 1 then the predicted values are statistically close to the observed ones; when the coefficient of determination $R^{2}$ is close to 1.0 then most of the variation of the observed values can be explained by the model. The root mean square error, RMSE characterizes the variance of the errors; the smaller RMSE the better is the model's performance.

The modelling efficiency, EF, was used to determine the relative magnitude of the residual variance comparatively to the measured data variance; it is defined from the ratio of the mean square error to the variance in the observed data (Nash and Sutcliffe, 1970; Moriasi et al., 2007). EF indicates that when the residual variance equals the observed data variance it results $\mathrm{EF}=1.0$; contrarily, when $\mathrm{EF}$ equals zero or is negative this indicates that the observed mean is as good or better predictor than the model. The Willmott (1981) index of agreement, $d_{\mathrm{IA}}$, is also a non-dimensional measure that represents the ratio between the mean square error and the "potential error", defined as the sum of the squared absolute values of the distances from the predicted values to the mean observed value and distances from the observed values to the mean observed value (Moriasi et al., 2007): $d_{\mathrm{IA}}$ varies between 0 and 1 ; a value of 1 indicates a perfect agreement between the measured and predicted values while 0 indicates no agreement at all (Moriasi et al., 2007).

The above statistics measure the degree of accuracy of $\mathrm{ET}_{0}$ estimation using PMT and HS methods with respect to the PM-ET, however not giving information whether the accuracy between the two competing models is significantly different. To address this issue, a test statistic proposed by Diebold and Mariano (1995), which is commonly used in financial literature, is adopted. Although this test is usually used for out-of-sample forecasting accuracy analysis (Mohammadi and Su, 2010), here it is used to test the accuracy of within-sample prediction following Modarres and Ouarda (2012), who recently applied it in hydrological sciences. In the present study, the test can indicate if there is a significant difference between PMT and HS's performances in estimating $\mathrm{ET}_{0}$. Formally, let $e_{1, \mathrm{t}}$ and $e_{2, t}, t=1, \ldots, m$, denote model errors from PMT an HS models and $g\left(e_{1, t}\right)$ and $g\left(e_{2, t}\right)$ are their associated loss functions, i.e., the squared-error loss, and $d t=g\left(e_{1}, t\right)-g\left(e_{2}, t\right)$ is the loss differential, then the $B$ statistics (Diebold and Mariano, 1995) is defined as:

$B=\frac{\bar{d}}{\sqrt{s / m}}$ 

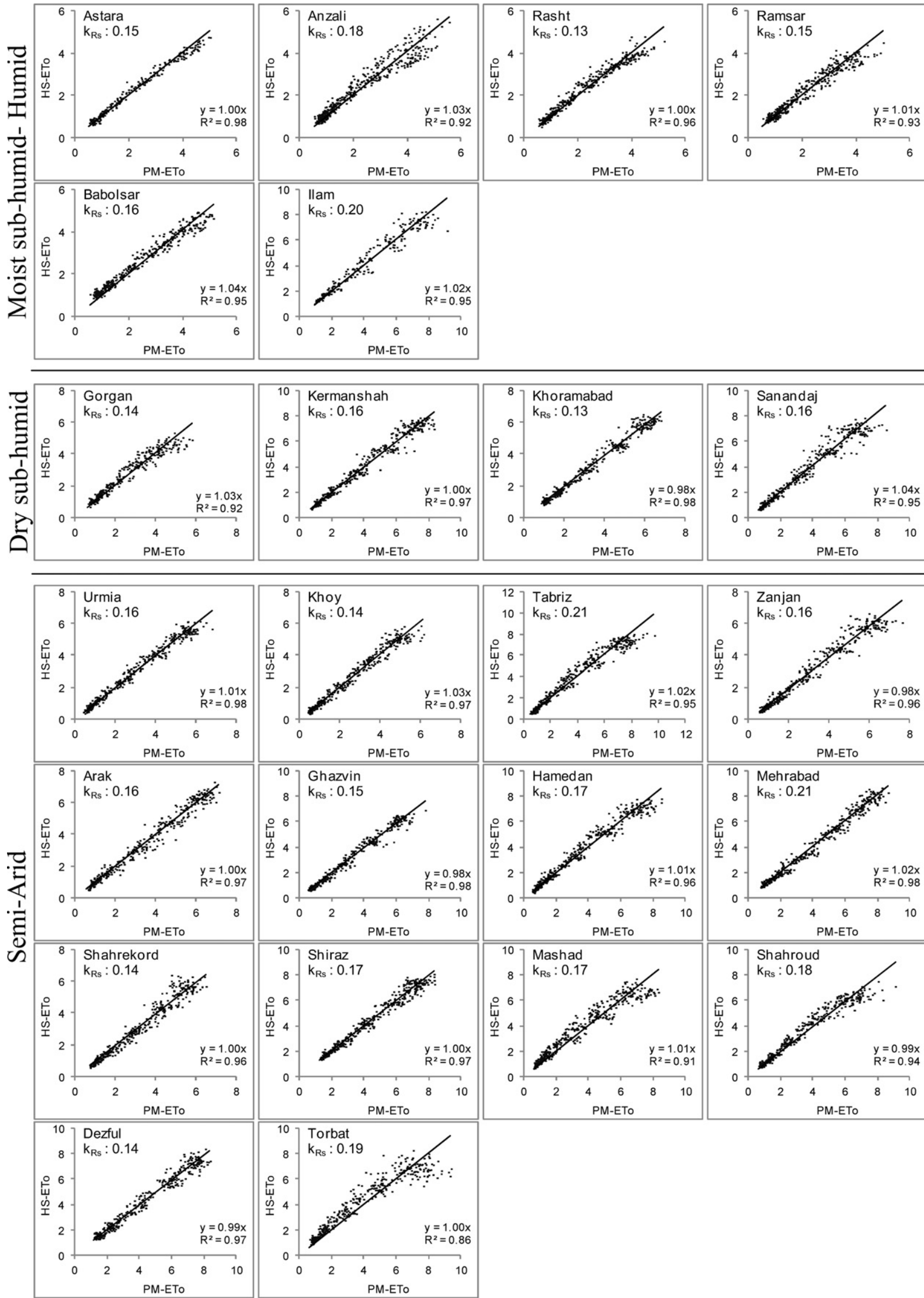

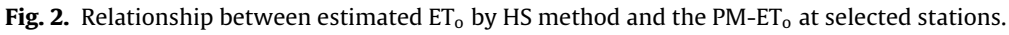



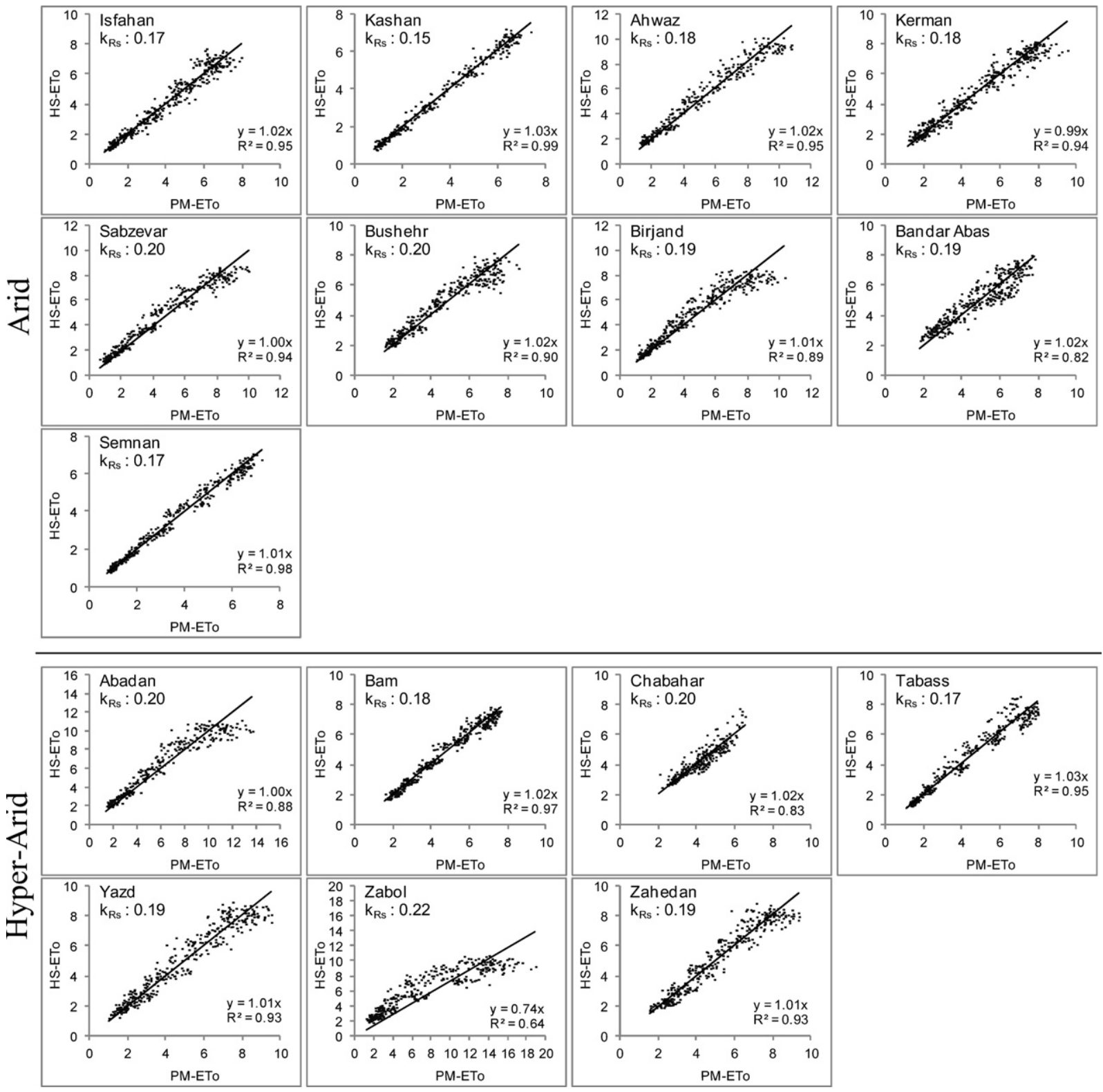

Fig. 2. (Continued).

where $\bar{d}$ is the sample mean, $s$ is the variance of loss differential and $m$ is the number of observations. Given covariance stationarity and short memory with regard to $d t$, the test implies an asymptotic distribution with zero mean and unit variance. Under a null hypothesis of zero mean, the two models have equal accuracy if the loss differential has zero expectation for all $t$ observations. The null hypothesis is rejected in favour of the alternative hypothesis when the statistic $B$, in absolute value, exceeds the critical value of a standard unit Gaussian distribution (Diebold and Mariano, 1995).

\section{Results}

\subsection{Performance of HS method}

The performance of the HS method is evaluated against the computed PM-ET ${ }_{0}$ in all considered stations (Fig. 2 and Table 3). Fig. 2

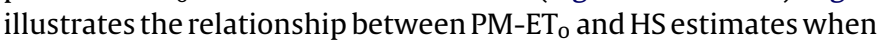
appropriate $k_{\mathrm{Rs}}$ were used for all the stations. In Table 3, in addition to the goodness of fit indicators, the appropriate $k_{\mathrm{Rs}}$ utilized for computing HS for each of the considered stations are also given.
Fig. 2 shows that the estimated HS strongly correlates with

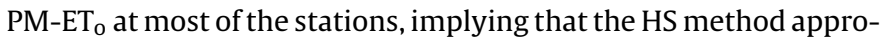

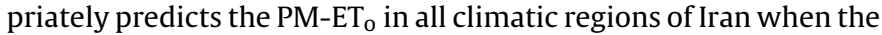
appropriate $k_{\mathrm{Rs}}$ is selected. A visual inspection in Fig. 2 and Table 3 suggests that the HS method performs well for all climatic zones of Iran shown in Fig. 1b, particularly for the stations characterized with semi arid to humid climates in western and northern Iran. The HS estimates for the stations located in the central-southern and eastern arid to hyper-arid climates of Iran show also a satisfactory agreement with $\mathrm{PM}-\mathrm{ET}_{0}$, though a very poor agreement was found for Zabol in eastern Iran. A slighter deviation of the HS estimation from the PM-ET $\mathrm{P}_{\mathrm{o}}$ for higher ET values was also observed for some other stations characterized with semi-arid to hyper-arid climates though are reasonably in good agreement. The observed deviation in such stations, particularly for extreme values, is supposed to be related to the effect of wind speed on $\mathrm{PM}-\mathrm{ET}_{0}$ computation that is addressed in Section 3.4.

Good results for humid climates (Fig. 2 and Table 3) are contradicting findings by many authors (e.g., Trajkovic and Kolakovic, 2009; Martinez and Thepadia, 2010; Tabari, 2010) and result from 
Table 3

Statistically comparing the performance of the HS with the PM-ET

\begin{tabular}{|c|c|c|c|c|c|c|c|}
\hline Climatic zone & Stations & $k_{\mathrm{Rs}}$ & $b$ & $R^{2}$ & $\operatorname{RMSE}\left(\mathrm{mm} \mathrm{d}^{-1}\right)$ & $\mathrm{EF}$ & $d_{\mathrm{IA}}$ \\
\hline \multirow[t]{5}{*}{ Humid } & Astara & 0.15 & 1.00 & 0.98 & 0.18 & 0.98 & 0.99 \\
\hline & Anzali & 0.18 & 1.03 & 0.92 & 0.37 & 0.96 & 0.98 \\
\hline & Rasht & 0.13 & 1.00 & 0.96 & 0.24 & 0.98 & 0.99 \\
\hline & Ramsar & 0.15 & 1.01 & 0.93 & 0.28 & 0.97 & 0.99 \\
\hline & Babolsar & 0.16 & 1.04 & 0.95 & 0.30 & 0.98 & 0.99 \\
\hline Moist sub-humid & Ilam & 0.20 & 1.02 & 0.95 & 0.52 & 0.99 & 0.99 \\
\hline \multirow[t]{4}{*}{ Dry sub-humid } & Gorgan & 0.14 & 1.03 & 0.92 & 0.38 & 0.98 & 0.99 \\
\hline & Kermanshah & 0.16 & 1.00 & 0.97 & 0.40 & 0.99 & 0.99 \\
\hline & Khoramabad & 0.13 & 0.98 & 0.98 & 0.28 & 0.99 & 1.00 \\
\hline & Sanandaj & 0.16 & 1.04 & 0.95 & 0.54 & 0.98 & 0.99 \\
\hline \multirow[t]{14}{*}{ Semi-arid } & Arak & 0.16 & 1.00 & 0.97 & 0.33 & 0.99 & 0.99 \\
\hline & Dezful & 0.14 & 0.99 & 0.97 & 0.41 & 0.98 & 0.99 \\
\hline & Ghazvin & 0.15 & 0.98 & 0.98 & 0.31 & 0.98 & 0.99 \\
\hline & Hamedan & 0.17 & 1.01 & 0.96 & 0.45 & 0.98 & 0.99 \\
\hline & Khoy & 0.14 & 1.03 & 0.97 & 0.30 & 0.98 & 0.99 \\
\hline & Mashhad & 0.17 & 1.01 & 0.91 & 0.62 & 0.96 & 0.98 \\
\hline & Mehrabad & 0.21 & 1.02 & 0.98 & 0.37 & 0.98 & 0.99 \\
\hline & Urmia & 0.16 & 1.01 & 0.98 & 0.27 & 0.98 & 0.99 \\
\hline & Shahrekord & 0.14 & 1.00 & 0.96 & 0.37 & 0.98 & 0.99 \\
\hline & Shahroud & 0.18 & 0.99 & 0.94 & 0.49 & 0.98 & 0.99 \\
\hline & Shiraz & 0.17 & 1.00 & 0.97 & 0.37 & 0.99 & 1.00 \\
\hline & Tabriz & 0.21 & 1.02 & 0.95 & 0.56 & 0.99 & 1.00 \\
\hline & Torbat & 0.19 & 1.00 & 0.86 & 0.81 & 0.91 & 0.97 \\
\hline & Zanjan & 0.16 & 0.98 & 0.96 & 0.40 & 0.99 & 0.99 \\
\hline \multirow[t]{9}{*}{ Arid } & Ahwaz & 0.18 & 1.02 & 0.95 & 0.64 & 0.95 & 0.99 \\
\hline & Bandar Abas & 0.19 & 1.02 & 0.82 & 0.63 & 0.94 & 0.97 \\
\hline & Birjand & 0.19 & 1.01 & 0.89 & 0.75 & 0.96 & 0.98 \\
\hline & Bushehr & 0.20 & 1.02 & 0.90 & 0.59 & 0.97 & 0.99 \\
\hline & Isfahan & 0.17 & 1.02 & 0.95 & 0.45 & 0.96 & 0.99 \\
\hline & Kashan & 0.15 & 1.03 & 0.99 & 0.27 & 0.99 & 1.00 \\
\hline & Kerman & 0.18 & 0.99 & 0.94 & 0.51 & 0.97 & 0.99 \\
\hline & Sabzevar & 0.20 & 1.00 & 0.94 & 0.62 & 0.98 & 0.99 \\
\hline & Semnan & 0.17 & 1.01 & 0.98 & 0.28 & 0.99 & 1.00 \\
\hline \multirow[t]{7}{*}{ Hyper-arid } & Abadan & 0.20 & 1.00 & 0.88 & 1.07 & 0.97 & 0.98 \\
\hline & Bam & 0.18 & 1.02 & 0.97 & 0.34 & 0.98 & 0.99 \\
\hline & Chabahar & 0.20 & 1.02 & 0.83 & 0.43 & 0.82 & 0.95 \\
\hline & Tabass & 0.17 & 1.03 & 0.95 & 0.55 & 0.95 & 0.99 \\
\hline & Yazd & 0.19 & 1.01 & 0.93 & 0.64 & 0.95 & 0.98 \\
\hline & Zabol & 0.22 & 0.74 & 0.64 & 2.86 & 0.68 & 0.86 \\
\hline & Zahedan & 0.19 & 1.01 & 0.93 & 0.60 & 0.92 & 0.98 \\
\hline
\end{tabular}

the calibration of $k_{\mathrm{Rs}}$, which was apparently not achieved by the referred authors.

Fig. 3a illustrates the spatial pattern of $k_{\mathrm{Rs}}$ appropriate for estimation of $\mathrm{ET}_{\mathrm{o}}$ using the HS method. The appropriate $k_{\mathrm{Rs}}$ for the stations located in the dry-sub-humid to humid climates of western and northern Iran found to be between 0.13 and 0.18 , while it ranges from 0.14 to 0.20 for the stations situated in the semiarid to hyper-arid climates of central, southern and eastern Iran. The figure depicts a gradual increasing in $k_{\mathrm{Rs}}$ moving from north to south and from west to east, being relatively in concordance of the climatic zones of Iran depicted in Fig. 1. However, the spatial configuration of the $k_{\mathrm{Rs}}$ is interrupted by some eyeballs, particularly in northern half of the country, wherever the $k_{\mathrm{Rs}}$ values are far different from the surrounding values. In other words, there are a few cases where the appropriate $k_{\mathrm{Rs}}$ for a single station differs from the general pattern of the region. For example the best fitted $k_{\mathrm{Rs}}$ for Tabriz, in north-western Iran, is 0.21 , which is much higher than the norm of the region, which could be attributed to the local high summer wind speed. Contrasting, $k_{\mathrm{Rs}}$ is 0.15 for Kashan, in central Iran, which is lower than the general $k_{\mathrm{Rs}}$ pattern for arid and hyper-arid climates.

The performance of the HS method in relation to the ${\mathrm{PM}-\mathrm{ET}_{\mathrm{O}} \text { was }}$ assessed through a set of goodness of fit indicators (Table 3 ). These statistics indicate that the HS method satisfactorily predicts $\mathrm{ET}_{0}$ in most of the stations, which is supported by $R^{2}$ higher than 0.90 and the regression coefficient $b$ between 0.98 and 1.02 in approximately $85 \%$ of the stations. The RMSE is lower than 0.70 and $0.50 \mathrm{~mm} \mathrm{~d}^{-1}$ in $90 \%$ and $63 \%$ of the stations, respectively. These results are supported with the modelling efficiency (EF), larger than 0.95 and the index of agreement $\left(d_{\mathrm{IA}}\right)$ higher than 0.99 in approximately $90 \%$ of stations. Differently, larger errors of estimate and lower goodness of fit indicators were obtained for Zabol, Abadan, Torbat, Birjand, Bandarabas, Sabzevar and Mashad, where the variance of the residuals of the estimation is high and does not respond to the required homoscedasticity, probably due to lack of considering wind speed within the HS method.

\subsection{Performance of the PMT method}

The performance of the PMT method against the PM-ET ${ }_{0}$ in all considered stations were also evaluated graphically (Fig. 4) and statistically (Table 4 ). $T_{\min }$ was corrected for all considered stations in semi-arid to hyper-arid climates (Table 2 ) in order to better estimate $T_{\text {dew }}$ for PMT computation. For humid climates, $T_{\text {dew }}$ was differently estimated with Eq. (7). A trial and error procedure was adopted to search for the appropriate $k_{\mathrm{Rs}}$ used for computation of PMT, their values are indicated in Fig. 4 and Table 4. For some stations, as analyzed in Section 3.4, wind speed corrections were also adopted. 


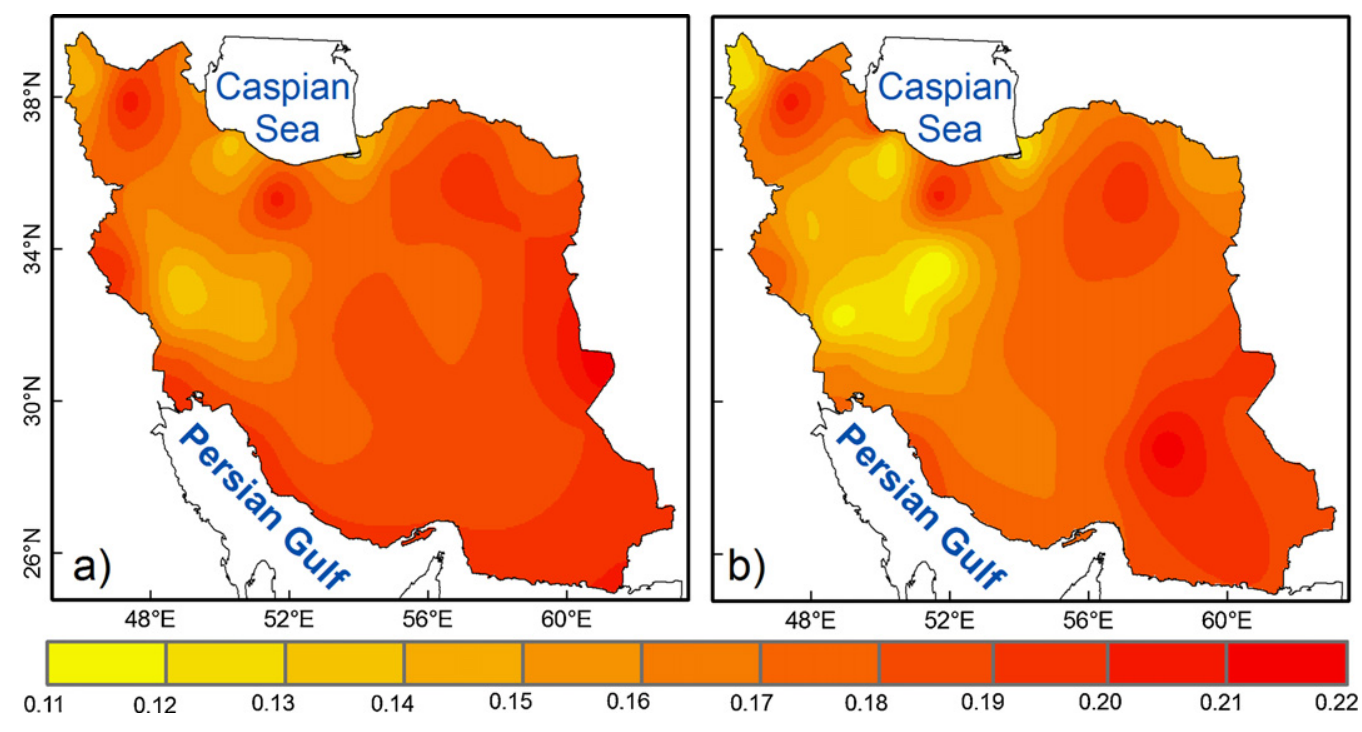

Fig. 3. Spatial patterns of the selected $k_{\mathrm{Rs}}$ over Iran for: (a) HS and (b) PMT methods.

As illustrated in Fig. 4, the estimated PMT strongly correlate lin-

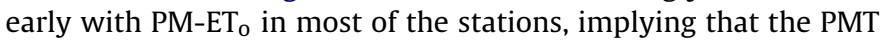
appropriately predicts the PM-ET ${ }_{0}$ in all climatic zones of Iran. Fig. 4 suggests that the PMT particularly performs well for the stations characterized with semi arid to humid climates of western and northern Iran. The PMT also performs reasonably well in humid climate of the Caspian Sea region in the north, where $T_{\text {dew }}$ was computed with Eq. (7), which allowed to consider the effect of high air

Table 4

Statistically comparing the performance of the PMT with PM-ET

\begin{tabular}{|c|c|c|c|c|c|c|c|}
\hline Climatic zone & Stations & $k_{\mathrm{Rs}}$ & $b$ & $R^{2}$ & $\operatorname{RMSE}\left(\mathrm{mm} \mathrm{d}^{-1}\right)$ & $\mathrm{EF}$ & $d_{\mathrm{IA}}$ \\
\hline \multirow[t]{5}{*}{ Humid } & Astara & 0.16 & 0.99 & 0.98 & 0.19 & 0.98 & 0.99 \\
\hline & Anzali & 0.20 & 1.00 & 0.94 & 0.32 & 0.94 & 0.99 \\
\hline & Rasht & 0.13 & 1.01 & 0.94 & 0.28 & 0.95 & 0.99 \\
\hline & Ramsar & 0.16 & 1.03 & 0.94 & 0.29 & 0.93 & 0.98 \\
\hline & Babolsar & 0.16 & 1.01 & 0.95 & 0.29 & 0.95 & 0.99 \\
\hline Moist sub-humid & Ilam & 0.19 & 0.99 & 0.96 & 0.44 & 0.96 & 0.99 \\
\hline \multirow[t]{4}{*}{ Dry sub-humid } & Gorgan & 0.12 & 1.01 & 0.93 & 0.36 & 0.93 & 0.98 \\
\hline & Kermanshah & 0.14 & 1.03 & 0.97 & 0.41 & 0.97 & 0.99 \\
\hline & Khoramabad & 0.10 & 1.00 & 0.94 & 0.41 & 0.95 & 0.99 \\
\hline & Sanandaj & 0.12 & 1.00 & 0.94 & 0.50 & 0.95 & 0.98 \\
\hline \multirow[t]{14}{*}{ Semi-arid } & Arak & 0.14 & 1.01 & 0.96 & 0.39 & 0.96 & 0.99 \\
\hline & Dezful & 0.10 & 0.99 & 0.93 & 0.55 & 0.94 & 0.98 \\
\hline & Ghazvin & 0.13 & 1.02 & 0.97 & 0.34 & 0.97 & 0.99 \\
\hline & Hamedan & 0.15 & 1.01 & 0.96 & 0.46 & 0.96 & 0.99 \\
\hline & Khoy & 0.11 & 1.03 & 0.94 & 0.39 & 0.94 & 0.98 \\
\hline & Mashhad & 0.15 & 1.01 & 0.90 & 0.62 & 0.93 & 0.98 \\
\hline & Mehrabad & 0.21 & 1.01 & 0.98 & 0.40 & 0.97 & 0.99 \\
\hline & Urmia & 0.14 & 1.00 & 0.97 & 0.30 & 0.97 & 0.99 \\
\hline & Shahrekord & 0.11 & 1.03 & 0.93 & 0.44 & 0.93 & 0.98 \\
\hline & Shahroud & 0.17 & 1.00 & 0.94 & 0.49 & 0.95 & 0.99 \\
\hline & Shiraz & 0.16 & 1.01 & 0.96 & 0.44 & 0.96 & 0.99 \\
\hline & Tabriz & 0.20 & 0.99 & 0.96 & 0.45 & 0.97 & 0.99 \\
\hline & Torbat & 0.18 & 1.02 & 0.87 & 0.79 & 0.90 & 0.97 \\
\hline & Zanjan & 0.14 & 0.99 & 0.96 & 0.39 & 0.96 & 0.99 \\
\hline \multirow[t]{9}{*}{ Arid } & Ahwaz & 0.18 & 1.02 & 0.92 & 0.81 & 0.93 & 0.98 \\
\hline & Bandar Abas & 0.17 & 1.00 & 0.90 & 0.46 & 0.92 & 0.98 \\
\hline & Birjand & 0.17 & 1.01 & 0.91 & 0.63 & 0.92 & 0.98 \\
\hline & Bushehr & 0.19 & 1.00 & 0.92 & 0.53 & 0.93 & 0.98 \\
\hline & Isfahan & 0.15 & 1.02 & 0.94 & 0.49 & 0.94 & 0.98 \\
\hline & Kashan & 0.11 & 1.00 & 0.96 & 0.36 & 0.97 & 0.99 \\
\hline & Kerman & 0.17 & 1.01 & 0.90 & 0.66 & 0.92 & 0.98 \\
\hline & Sabzevar & 0.20 & 1.01 & 0.95 & 0.55 & 0.96 & 0.99 \\
\hline & Semnan & 0.16 & 1.03 & 0.98 & 0.28 & 0.98 & 0.99 \\
\hline \multirow[t]{7}{*}{ Hyper-arid } & Abadan & 0.21 & 1.01 & 0.89 & 1.06 & 0.90 & 0.95 \\
\hline & Bam & 0.16 & 1.01 & 0.97 & 0.33 & 0.97 & 0.99 \\
\hline & Chabahar & 0.18 & 1.01 & 0.88 & 0.36 & 0.87 & 0.97 \\
\hline & Tabass & 0.15 & 1.01 & 0.92 & 0.61 & 0.94 & 0.98 \\
\hline & Yazd & 0.18 & 1.00 & 0.92 & 0.63 & 0.93 & 0.98 \\
\hline & Zabol & 0.20 & 0.67 & 0.67 & 3.29 & 0.53 & 0.81 \\
\hline & Zahedan & 0.18 & 0.99 & 0.92 & 0.58 & 0.93 & 0.98 \\
\hline
\end{tabular}


humidity. The estimated PMT for most of the stations located in the central-southern and eastern arid and hyper-arid climates of Iran show also satisfactory agreement with $\mathrm{PM}-\mathrm{ET}_{0}$, though relatively weak association were found for Abadan, Torbat, Birjand, Chabahar and, mainly, for Zabol station (Fig. 4 and Table 4). All these stations also performed poorly for the HS method.

The stations located in western and northern dry-sub-humid to humid climates of Iran have $k_{\mathrm{Rs}}$ between 0.10 and 0.18 , while $k_{\mathrm{Rs}}$
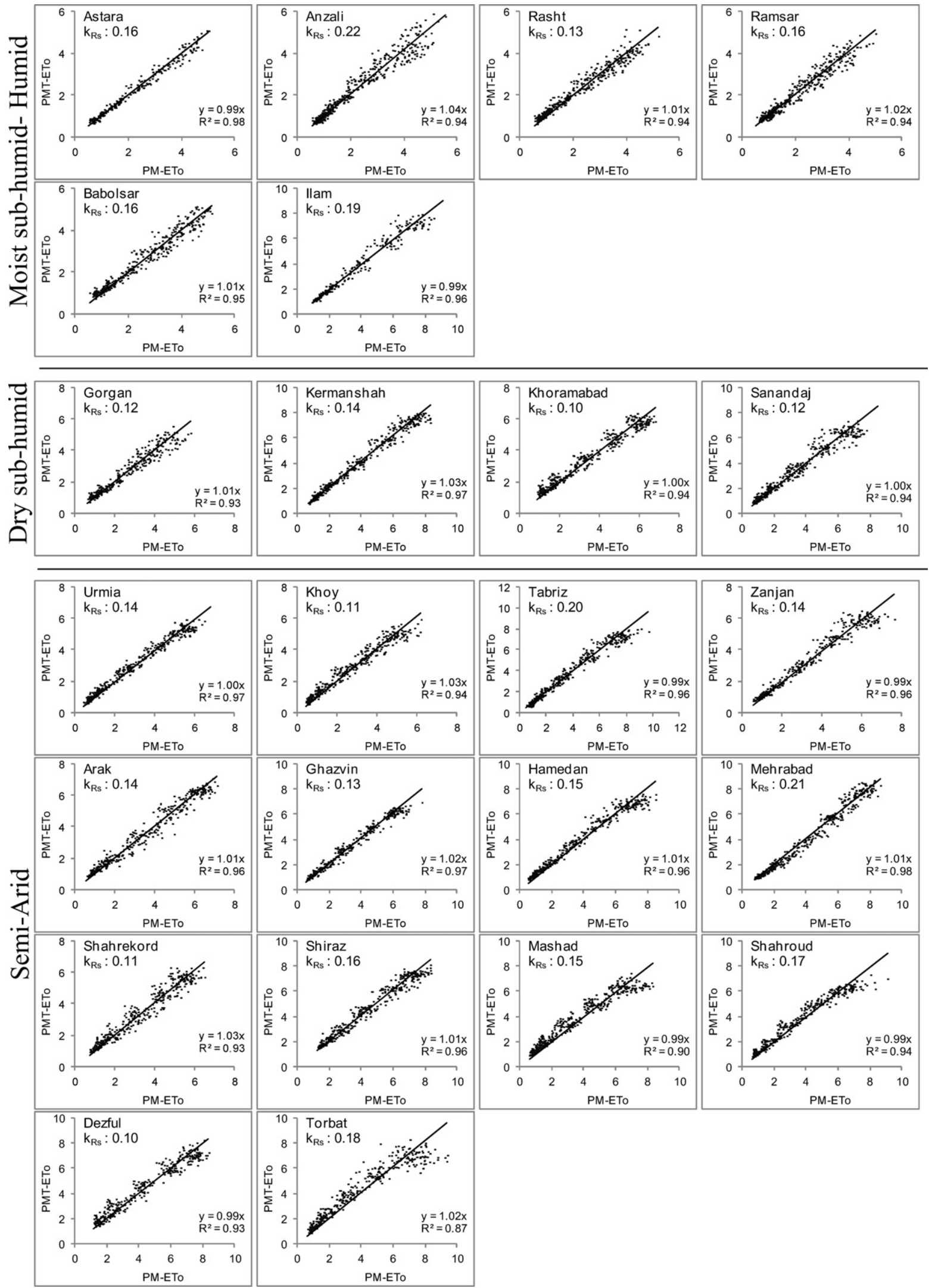

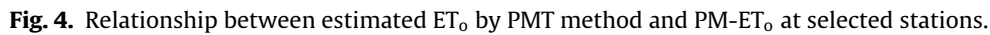



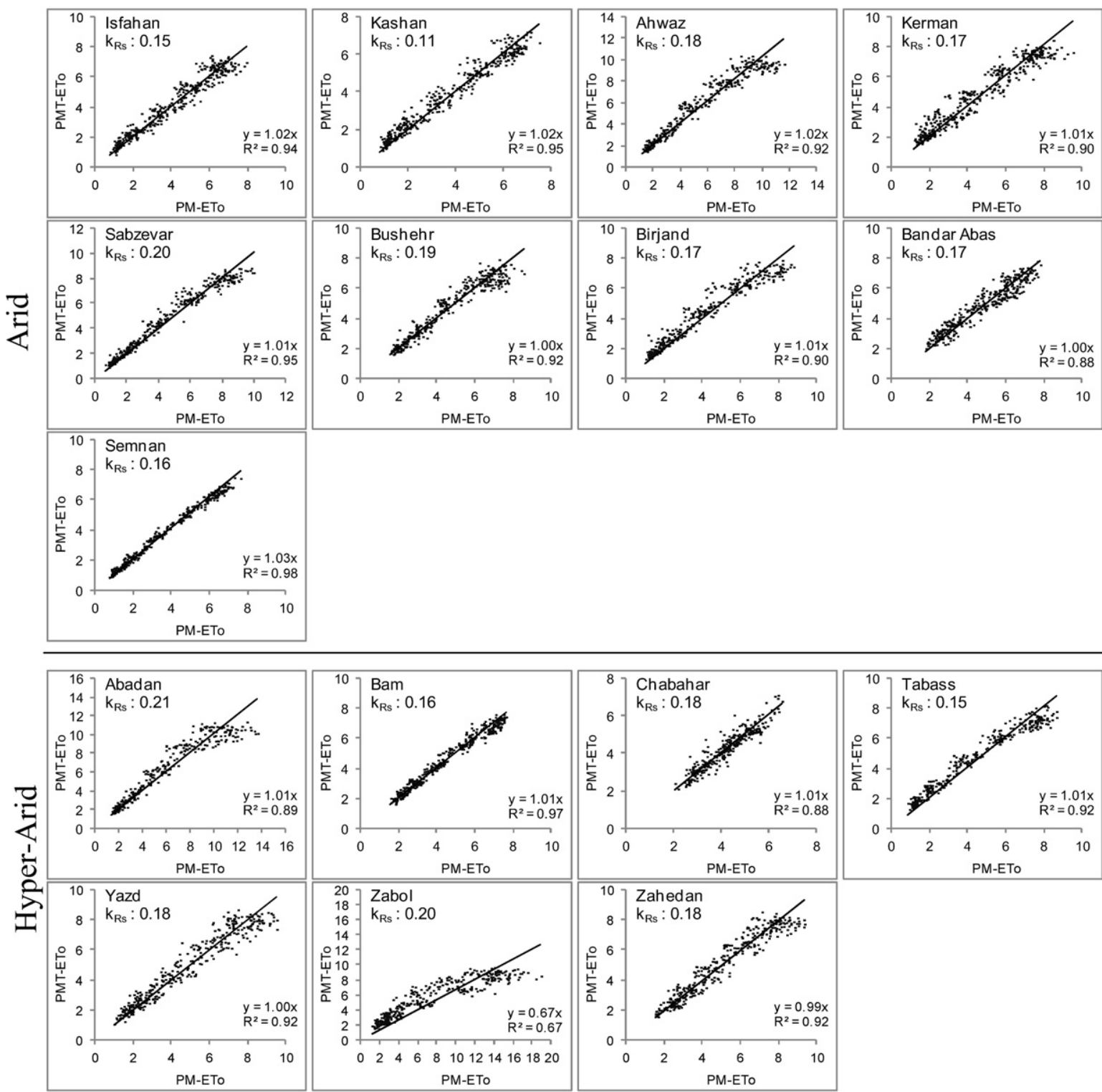

Fig. 4. (Continued).

varies from 0.11 to 0.20 for the stations situated in the semi-arid to hyper-arid regions of central-eastern Iran (Table 4 and Fig. 3b). As was the case for the HS method, there are some cases where the selected $k_{\mathrm{Rs}}$ for a station differs from the regional pattern, e.g., the selected $k_{\mathrm{Rs}}$ for Tabriz station in north-western Iran is much higher than the $k_{\mathrm{Rs}}$ values of the surrounding stations. Fig. 3b shows the spatial pattern of $k_{\mathrm{Rs}}$ used for estimation of PMT over Iran, depicting a pattern very similar of that for the HS method in Fig. 3a. Apparently, the $k_{\mathrm{Rs}}$ is influenced by elevation, topography and the aridity index though in the present study weak correlations (not shown) were found between the aforementioned factors and the $k_{\mathrm{Rs}}$ values relative to both the PMT and HS methods.

The statistics shown in Table 4 indicate that the PMT method satisfactorily predicts $\mathrm{ET}_{\mathrm{o}}$ in most of the stations, which is supported by $R^{2}$ higher than 0.90 and $b$ coefficient between 0.98 and 1.02 in 90 and $85 \%$ of the stations, respectively. The RMSE is lower than 0.70 and $0.50 \mathrm{~mm} \mathrm{~d}^{-1}$ in $90 \%$ and $68 \%$ of the cases, EF and $d_{\mathrm{IA}}$ were $\geq 0.90$ and $\geq 0.98$ for more than $90 \%$ of the stations. These results are only slightly better than the corresponding results for the HS method in Table 3. Results suggest a good estimation of $\mathrm{ET}_{0}$ with
PMT, particularly for practical irrigation scheduling and for using in drought indices computation such as the PDSI (e.g., Paulo et al., 2012). Results indicate that the use of PMT method for $\mathrm{ET}_{0}$ estimation in the study area is worthwhile when only limited data are available. However, coefficients of determination $<0.90$ for Zabol, Chabahar, Abadan and Torbat suggest that the estimated PMT in these stations substantially deviates from the PM-ET ${ }_{0}$. The achieved results for PMT are consistent with those obtained for HS, which

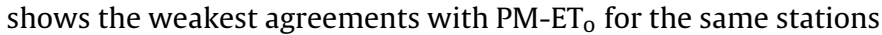
as PMT.

\subsection{Role of temperature adjustment for $T_{\text {dew }}$ estimation}

The effectiveness of temperature adjustment in improving the PMT estimation was statistically evaluated for all considered stations, by comparing the regression coefficient $b, R^{2}$ and RMSE statistics relating PMT and PM-ET $\mathrm{E}_{0}$ data, before and after temperature adjustment (Table 5).

Results suggested that temperature adjustments for humid and sub-humid climates, i.e., computing $T_{\text {dew }}$ from Eq. (7) instead of 
Table 5

Statistically assessment of the effects of temperature adjustment in PMT estimation.

\begin{tabular}{|c|c|c|c|c|c|c|c|c|}
\hline \multirow[t]{2}{*}{ Climatic zone } & \multirow[t]{2}{*}{ Stations } & \multirow[t]{2}{*}{$k_{\mathrm{Rs}}$} & \multicolumn{3}{|c|}{ Before correction } & \multicolumn{3}{|c|}{ After correction } \\
\hline & & & $b$ & $R^{2}$ & $\operatorname{RMSE}\left(\mathrm{mm} \mathrm{d}^{-1}\right)$ & $b$ & $R^{2}$ & $\operatorname{RMSE}\left(\mathrm{mm} \mathrm{d}^{-1}\right)$ \\
\hline \multirow[t]{5}{*}{ Humid } & Astara & 0.16 & 1.00 & 0.96 & 0.24 & 0.99 & 0.98 & 0.19 \\
\hline & Anzali & 0.20 & 0.97 & 0.91 & 0.37 & 1.00 & 0.94 & 0.32 \\
\hline & Rasht & 0.13 & 1.05 & 0.88 & 0.39 & 1.01 & 0.94 & 0.28 \\
\hline & Ramsar & 0.16 & 1.01 & 0.88 & 0.33 & 1.03 & 0.94 & 0.29 \\
\hline & Babolsar & 0.16 & 0.97 & 0.88 & 0.38 & 1.01 & 0.95 & 0.29 \\
\hline Moist sub-humid & Ilam & 0.19 & 0.89 & 0.95 & 0.65 & 0.99 & 0.96 & 0.44 \\
\hline \multirow[t]{4}{*}{ Dry sub-humid } & Gorgan & 0.12 & 0.97 & 0.80 & 0.47 & 1.01 & 0.93 & 0.36 \\
\hline & Kermanshah & 0.14 & 0.96 & 0.96 & 0.44 & 1.03 & 0.97 & 0.41 \\
\hline & Khoramabad & 0.10 & 0.97 & 0.94 & 0.43 & 1.00 & 0.94 & 0.41 \\
\hline & Sanandaj & 0.12 & 0.93 & 0.92 & 0.59 & 1.00 & 0.94 & 0.50 \\
\hline \multirow[t]{14}{*}{ Semi-arid } & Arak & 0.14 & 0.94 & 0.95 & 0.44 & 1.01 & 0.96 & 0.39 \\
\hline & Dezful & 0.10 & 0.91 & 0.89 & 0.75 & 0.99 & 0.93 & 0.55 \\
\hline & Ghazvin & 0.13 & 0.95 & 0.96 & 0.38 & 1.02 & 0.97 & 0.34 \\
\hline & Hamedan & 0.15 & 0.95 & 0.95 & 0.51 & 1.01 & 0.96 & 0.46 \\
\hline & Khoy & 0.11 & 0.98 & 0.92 & 0.41 & 1.03 & 0.94 & 0.39 \\
\hline & Mashhad & 0.15 & 0.93 & 0.87 & 0.73 & 1.01 & 0.90 & 0.62 \\
\hline & Mehrabad & 0.21 & 0.90 & 0.98 & 0.57 & 1.01 & 0.98 & 0.40 \\
\hline & Urmia & 0.14 & 0.95 & 0.95 & 0.38 & 1.00 & 0.97 & 0.30 \\
\hline & Shahrekord & 0.11 & 0.99 & 0.91 & 0.45 & 1.03 & 0.93 & 0.44 \\
\hline & Shahroud & 0.17 & 0.91 & 0.93 & 0.77 & 1.00 & 0.94 & 0.49 \\
\hline & Shiraz & 0.16 & 0.95 & 0.95 & 0.51 & 1.01 & 0.96 & 0.44 \\
\hline & Tabriz & 0.20 & 0.88 & 0.95 & 0.70 & 0.99 & 0.96 & 0.45 \\
\hline & Torbat & 0.18 & 0.90 & 0.83 & 0.88 & 1.01 & 0.88 & 0.77 \\
\hline & Zanjan & 0.14 & 0.93 & 0.95 & 0.46 & 0.99 & 0.96 & 0.39 \\
\hline \multirow[t]{9}{*}{ Arid } & Ahwaz & 0.18 & 0.95 & 0.92 & 0.80 & 1.02 & 0.92 & 0.81 \\
\hline & Bandar Abas & 0.17 & 0.87 & 0.79 & 0.84 & 1.00 & 0.88 & 0.51 \\
\hline & Birjand & 0.17 & 0.93 & 0.89 & 0.68 & 1.01 & 0.91 & 0.63 \\
\hline & Bushehr & 0.19 & 0.89 & 0.88 & 0.78 & 1.00 & 0.92 & 0.52 \\
\hline & Isfahan & 0.15 & 0.93 & 0.93 & 0.56 & 1.02 & 0.94 & 0.49 \\
\hline & Kashan & 0.11 & 0.91 & 0.96 & 0.50 & 1.00 & 0.96 & 0.36 \\
\hline & Kerman & 0.17 & 0.94 & 0.90 & 0.68 & 1.01 & 0.90 & 0.66 \\
\hline & Sabzevar & 0.20 & 0.91 & 0.94 & 0.71 & 1.01 & 0.95 & 0.55 \\
\hline & Semnan & 0.16 & 0.94 & 0.98 & 0.36 & 1.03 & 0.98 & 0.28 \\
\hline \multirow[t]{7}{*}{ Hyper-arid } & Abadan & 0.21 & 0.95 & 0.89 & 1.05 & 1.01 & 0.89 & 1.06 \\
\hline & Bam & 0.16 & 0.90 & 0.96 & 0.56 & 1.01 & 0.97 & 0.33 \\
\hline & Chabahar & 0.18 & 0.84 & 0.73 & 0.80 & 1.01 & 0.88 & 0.36 \\
\hline & Tabass & 0.15 & 0.93 & 0.91 & 0.69 & 1.01 & 0.92 & 0.61 \\
\hline & Yazd & 0.18 & 0.92 & 0.92 & 0.73 & 1.00 & 0.92 & 0.63 \\
\hline & Zabol & 0.20 & 0.61 & 0.66 & 3.67 & 0.67 & 0.67 & 3.29 \\
\hline & Zahedan & 0.18 & 0.92 & 0.92 & 0.71 & 0.99 & 0.92 & 0.58 \\
\hline
\end{tabular}

simply using $T_{\min }$, considerably improves PMT estimation, where $b$ and $R^{2}$ increased and RMSE decreased after temperature adjustment for all stations characterized with humid and sub-humid climates of Iran. As an example, the coefficient of determination for Rasht and Ramsar stations increased from 0.88 to 0.94 after temperature correction; for Ilam, RMSE decreased from 0.65 to $0.44 \mathrm{~mm} \mathrm{~d}^{-1}$. These results indicate that the good performance of PMT estimation analyzed in the previous section is largely due to temperature adjustment for humidity.

Temperature adjustment for stations situated in semi-arid, arid and hyper-arid climates of Iran also showed to have improved $\mathrm{ET}_{\mathrm{o}}$ estimation. Differently from humid climates where temperature adjustment noticeably improved the $R^{2}$ statistic, the influence of temperature adjustment in semi arid to hyper-arid climates largely consisted in substantially increasing the regression coefficient, with $b$ approaching the 1:1 line. These results indicate that the temperature adjustment for aridity, with lowering $T_{\text {dew }}$ relative to raw $T_{\min }$, leads to overcome the common under estimation of PMT in arid conditions. Meanwhile, despite negligible improvements of $R^{2}$, noticeable improvements in RMSE statistic were observed for most of the stations situated in semi-arid, arid and hyper-arid climates. This fact suggests that temperature adjustment is of paramount importance for PMT estimation in such climates.

\subsection{Role of wind speed in PMT estimation}

As were shown in Figs. 2 and 4, the estimated $\mathrm{ET}_{0}$ by the HS and PMT methods show poor agreement with the ${\mathrm{PM}-\mathrm{ET}_{\mathrm{o}} \text { at some }}$ stations situated in the very dry climate of eastern and southern Iran, where HS and PMT methods largely underestimate $\mathrm{ET}_{\mathrm{o}}$ for the warm season. In exploring the possible factor responsible for the observed disagreement, we noticed that the considered stations are located in the area where extreme wind speed occurs, particularly in the summer.

The spatial pattern of the mean seasonal wind speed over the country is depicted in Fig. 5 to support an analysis about the possible role played by the wind factor in $\mathrm{ET}_{0}$ estimation. In Fig. $5 \mathrm{a}$ and $d$ it is evident that the mean autumn and winter wind speed do not exceed $2 \mathrm{~m} \mathrm{~s}^{-1}$ in most parts of the country except for a narrow band in southern and eastern Iran, where wind speed is between 3 and $4 \mathrm{~ms}^{-1}$. Fig. 5b shows an increase of wind speed in southern and eastern parts of Iran during spring, contrarily to northern half of the country. Differently, wind speed in summer increases drastically in eastern Iran (Fig. 5c), where it may exceed $8 \mathrm{~m} \mathrm{~s}^{-1}$. These data indicate that the mean seasonal wind speed in southern and eastern Iran, particularly for the warm spring and summer seasons, is often much higher than the common default value of $2 \mathrm{~m} \mathrm{~s}^{-1}$ used for PMT estimation, thus leading to substantial 

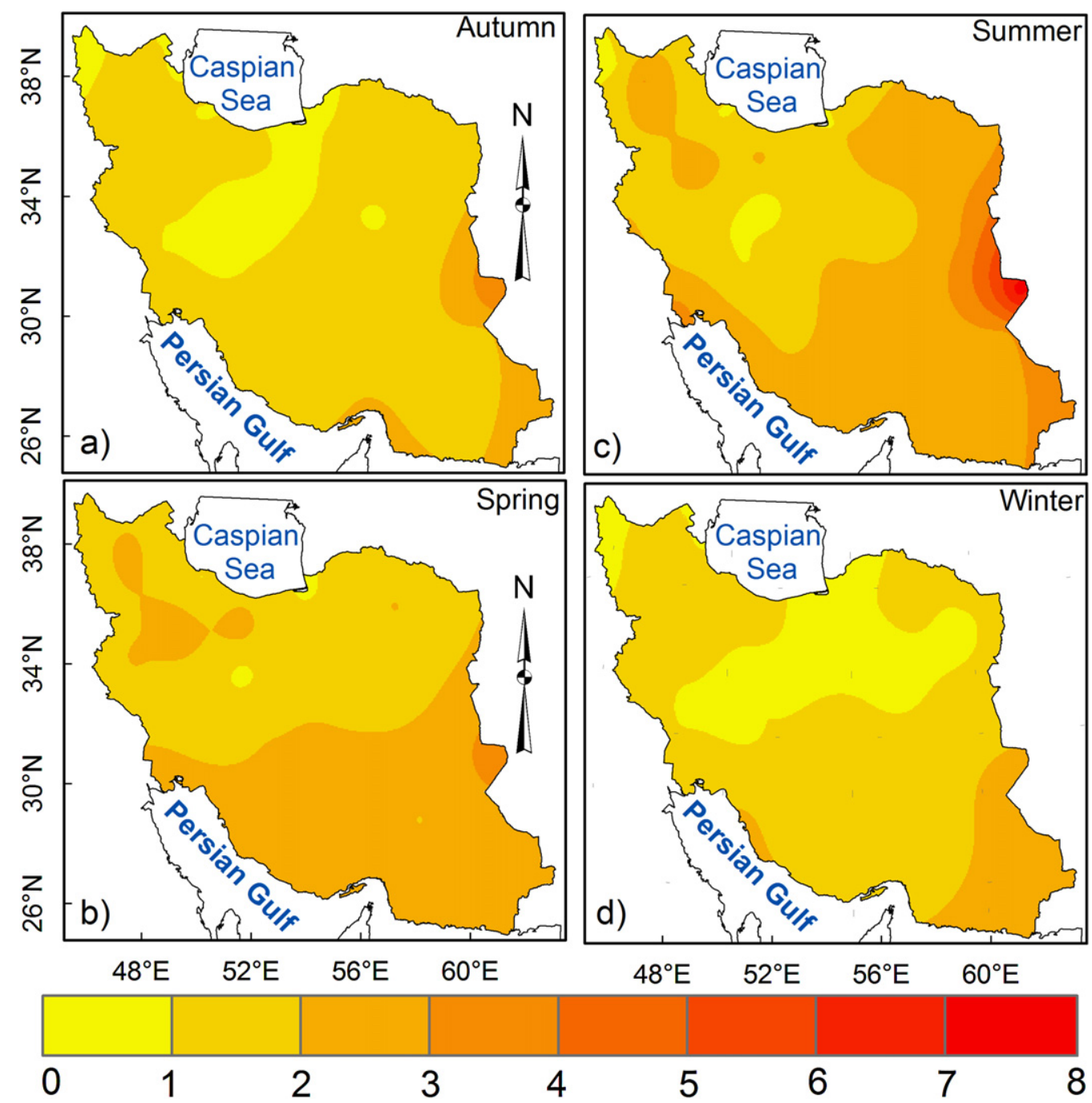

Fig. 5. Spatial patterns of mean seasonal wind speed $\left(\mathrm{m} \mathrm{s}^{-1}\right)$ over Iran for: (a) autumn, (b) spring, (c) summer and (d) winter.

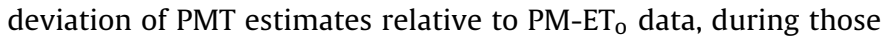

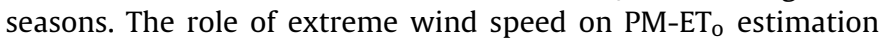
may be very important, mainly when it is associated with very hot weather in summer, which calls for using an estimate of wind speed different than that of the default value of $2 \mathrm{~m} \mathrm{~s}^{-1}$. Since the HS equation does not include any wind speed parameter, its results are likely underestimating $\mathrm{ET}_{\mathrm{o}}$ in windy and hot conditions like Zabol and various other stations located in arid and hyper-arid climates of southern and eastern Iran (Fig. 2).

As depicted in Fig. 5, the highest wind speed, particularly in summer, is observed in Zabol, eastern Iran, where the PMT and HS estimations have shown the worst agreement with the PM-ET (Figs. 2 and 4). This results from the fact that the observed wind speed in this station is several times higher than the default value of $2 \mathrm{~m} \mathrm{~s}^{-1}$, particularly during the very hot summer and late spring. The summer wind speed is also considerably higher than $2 \mathrm{~m} \mathrm{~s}^{-1}$ in Abadan, Sabzevar, Birjand, Torbat, Shahroud and Mashad stations in southern and eastern Iran, where the $\mathrm{ET}_{0}$ estimated by PMT and HS have shown a weak agreement with the PM-ET $\mathrm{E}_{0}$ for extreme $\mathrm{ET}_{0}$ values. The summer wind speed is also higher than the fixed value of $2 \mathrm{~m} \mathrm{~s}^{-1}$ in Tabriz, north-western Iran, giving rise to a wide dispersion of the highest $\mathrm{ET}_{0}$ values in the scatter plots of this station (Figs. 2 and 4). In most of these stations, the higher deviation of the PMT (and HS) estimations from the PM-ET ${ }_{0}$ correspond to the extreme $\mathrm{ET}_{0}$ values that occurred in the warm season of the year.
Therefore, the observed disagreement between the PMT (and HS)

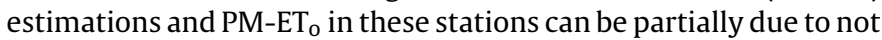
considering the wind speed influence in HS method and a default value of only $2 \mathrm{~m} \mathrm{~s}^{-1}$ in PMT, which is much smaller than the actual

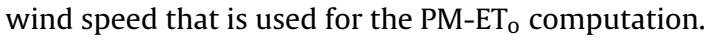

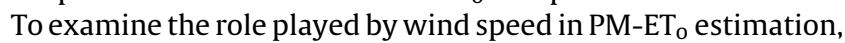
Fig. 6 illustrates the relationship between estimated $\mathrm{ET}_{0}$ by PMT and $\mathrm{PM}-\mathrm{ET}_{\mathrm{o}}$ at some selected stations, considering different scenarios:

(1) using the default wind speed value of $2 \mathrm{~m} \mathrm{~s}^{-1}$ in PMT computations,

(2) considering only the PM-ET $\mathrm{O}_{\mathrm{O}}$ data corresponding to wind speed not exceeding $2 \mathrm{~m} \mathrm{~s}^{-1}$,

(3) using observed local wind speed in PMT replacing the default wind speed value, and

(4) using average seasonal wind speed to replace the default value of $2 \mathrm{~m} \mathrm{~s}^{-1}$ in PMT computation.

As shown in Fig. 6a-f, the PMT method extremely underestimates $\mathrm{ET}_{\mathrm{o}}$ values corresponding to the summers in Shahroud, Mashad, Torbat, Abadan, Birjand and Zabol stations, thus leading to very low coefficients of determination, even though the optimum $b$ slope could be achieved for some. By excluding the observations with wind speed $>2 \mathrm{~m} \mathrm{~s}^{-1}$ from the analysis (scenario 2), the association between the PMT and PM-ET ${ }_{0}$ noticeably improved, with 

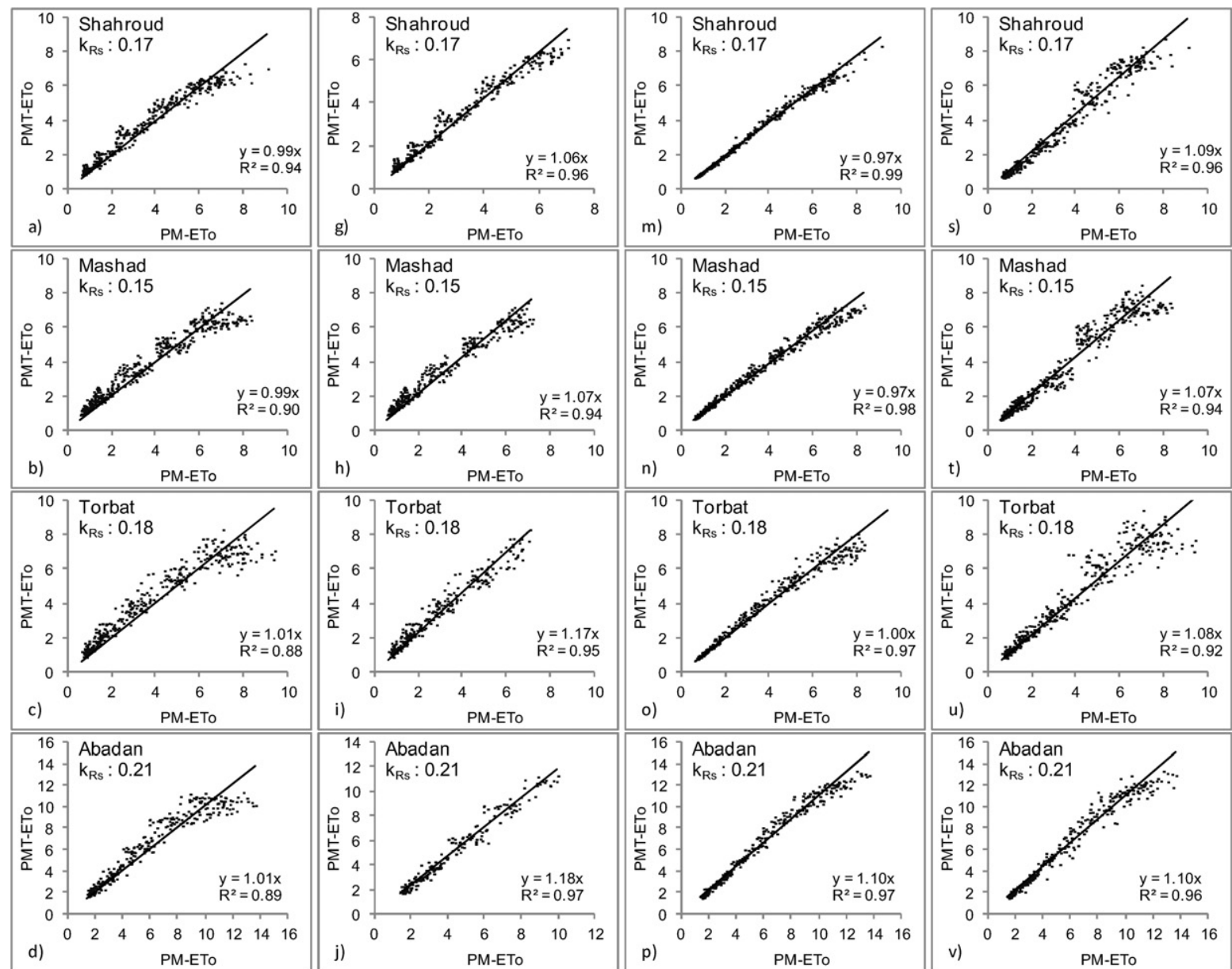

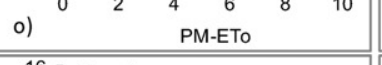
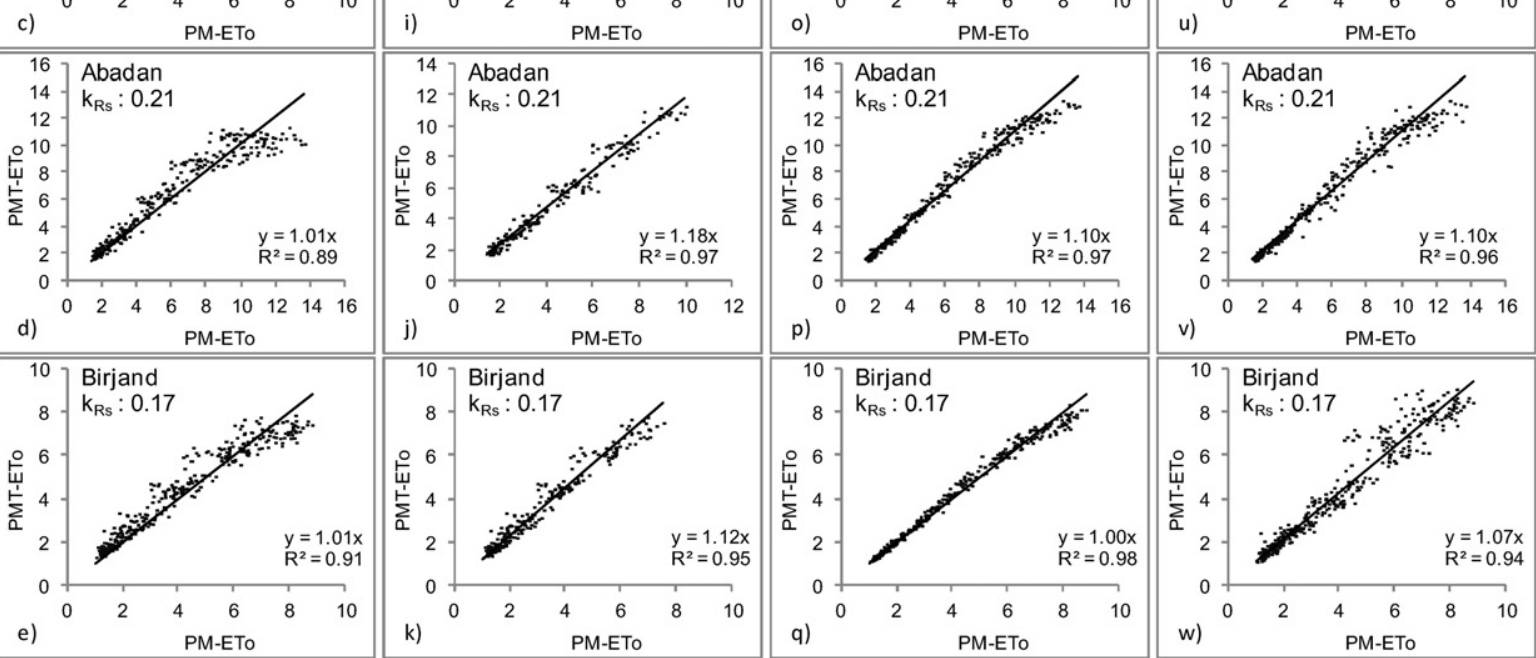

v) PM-ETo
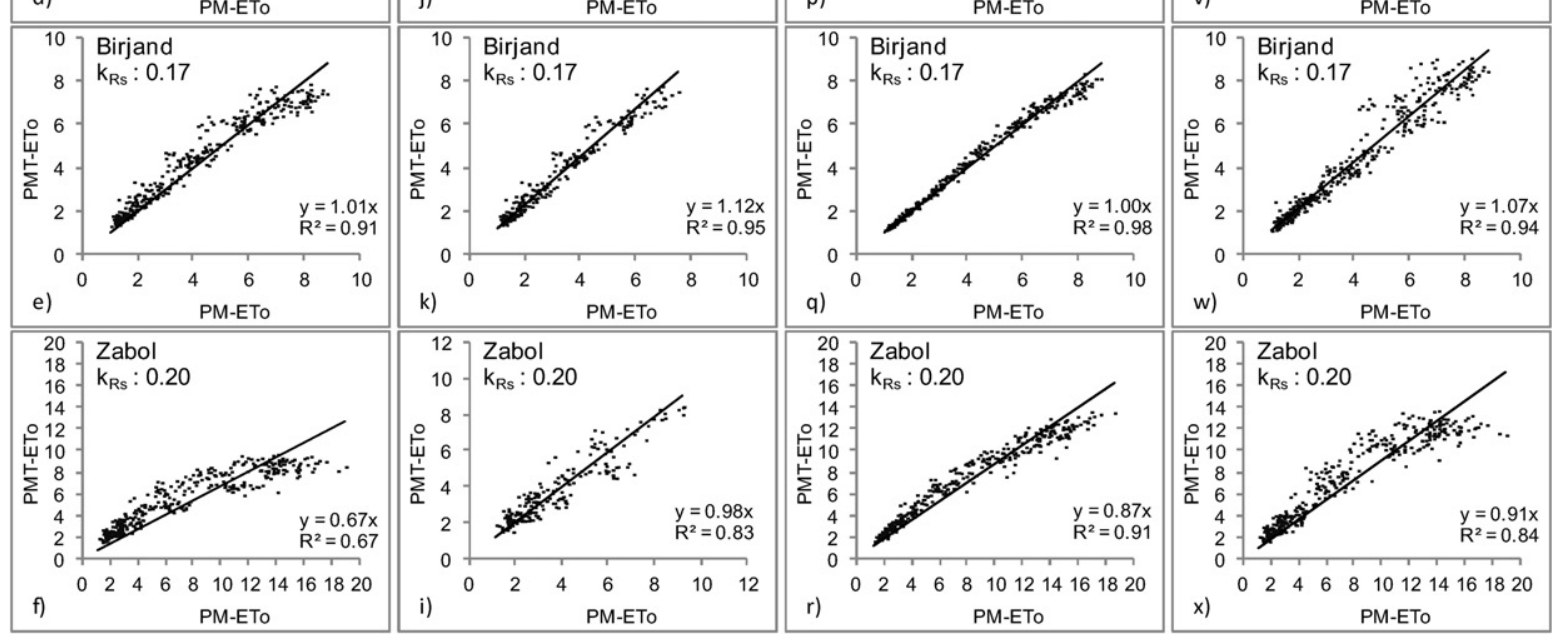

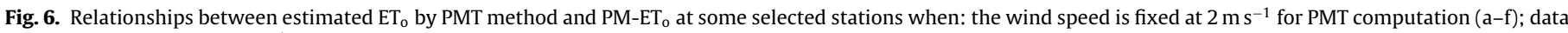

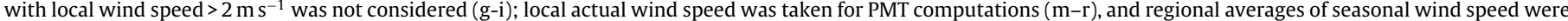
used for PMT computations ( $\mathrm{s}-\mathrm{x})$.

increased coefficients of determination and reduced residuals of the variance represented by a narrower dispersion band of the scatter plots shown in Fig. 6g-1. To further justify the role of wind speed in the association between the PMT and PM-ET ${ }_{0}$, Fig. $6 \mathrm{~m}-\mathrm{r}$ illustrates that the association between the two models substantially improved when local wind speed was used for PMT computation rather than the default value (scenario 3 ). Differently from discussions in the literature suggesting that wind speed has very low impact on $\mathrm{ET}_{0}$ estimation, the results obtained with scenario 3 illustrated that it is an important factor in arid and semi-arid climates when the stations are exposed to extreme wind speed, particularly in hot seasons. As an example, Fig. 6 f shows the scatter plot for the extremely windy station of Zabol, in eastern Iran, which is well known for its extreme summer wind speed that usually dominates the region for the whole summer time (Fig. 5c). As is depicted in Fig. $6 \mathrm{f}$ both $R^{2}$ and $b$ are very low for scenario 1 , thus indicating a very poor estimation of ET $_{0}$ by PMT. Substantial improvement was observed for scenario 2, when the data with extreme wind speed (wind speed $>4 \mathrm{~m}^{-1}$ ) were excluded, which led to a considerable improvement of $R^{2}$ and $b$ (Fig. 6l). It is worth nothing that 
Table 6

The Diebold and Mariano (1995) $B$ test for equal accuracy of PMT and HS methods (statistically significant $B$ statistics are in bold).

\begin{tabular}{|c|c|c|c|c|}
\hline Climatic zone & Stations & B Statistic & RMSE (PMT) & RMSE (HS) \\
\hline \multirow[t]{5}{*}{ Humid } & Astara & 0.75 & 0.19 & 0.18 \\
\hline & Anzali & -5.82 & 0.32 & 0.37 \\
\hline & Rasht & 4.10 & 0.28 & 0.24 \\
\hline & Ramsar & 0.15 & 0.29 & 0.28 \\
\hline & Babolsar & -1.38 & 0.29 & 0.30 \\
\hline Moist sub-humid & Ilam & -4.57 & 0.44 & 0.52 \\
\hline \multirow[t]{4}{*}{ Dry sub-humid } & Gorgan & -1.65 & 0.36 & 0.38 \\
\hline & Kermanshah & 0.90 & 0.41 & 0.40 \\
\hline & Khoramabad & -2.24 & 0.41 & 0.28 \\
\hline & Sanandaj & -1.31 & 0.49 & 0.54 \\
\hline \multirow[t]{14}{*}{ Semi-arid } & Arak & 3.97 & 0.39 & 0.33 \\
\hline & Dezful & 6.71 & 0.55 & 0.41 \\
\hline & Ghazvin & 1.53 & 0.34 & 0.31 \\
\hline & Hamedan & 1.13 & 0.46 & 0.45 \\
\hline & Khoy & 5.16 & 0.39 & 0.30 \\
\hline & Mashhad & 0.18 & 0.62 & 0.62 \\
\hline & Mehrabad & 2.58 & 0.40 & 0.37 \\
\hline & Urmia & 4.98 & 0.30 & 0.27 \\
\hline & Shahrekord & 5.60 & 0.44 & 0.37 \\
\hline & Shahroud & 0.07 & 0.49 & 0.49 \\
\hline & Shiraz & 5.69 & 0.44 & 0.37 \\
\hline & Tabriz & -7.88 & 0.45 & 0.56 \\
\hline & Torbat & -1.69 & 0.77 & 0.81 \\
\hline & Zanjan & -1.25 & 0.39 & 0.40 \\
\hline \multirow[t]{9}{*}{ Arid } & Ahwaz & 5.87 & 0.81 & 0.64 \\
\hline & Bandar Abas & -9.72 & 0.51 & 0.63 \\
\hline & Birjand & 2.03 & 0.63 & 0.75 \\
\hline & Bushehr & -5.09 & 0.52 & 0.59 \\
\hline & Isfahan & 7.72 & 0.49 & 0.45 \\
\hline & Kashan & 1.08 & 0.36 & 0.27 \\
\hline & Kerman & 7.94 & 0.66 & 0.51 \\
\hline & Sabzevar & -5.19 & 0.55 & 0.62 \\
\hline & Semnan & -0.55 & 0.28 & 0.28 \\
\hline \multirow[t]{7}{*}{ Hyper-arid } & Abadan & 0.67 & 1.06 & 1.07 \\
\hline & Bam & -2.25 & 0.33 & 0.34 \\
\hline & Chabahar & -3.23 & 0.36 & 0.43 \\
\hline & Tabass & 1.95 & 0.61 & 0.55 \\
\hline & Yazd & -0.51 & 0.63 & 0.64 \\
\hline & Zabol & 12.02 & 3.29 & 2.86 \\
\hline & Zahedan & -0.49 & 0.58 & 0.60 \\
\hline
\end{tabular}

the selected threshold for Zabol was set to wind speed $>4 \mathrm{~m}^{-1}$ since very few cases have wind speed $<2 \mathrm{~m}^{-1}$. Fig. $6 \mathrm{r}$ also demonstrates a much improved goodness of fit when local wind speed was used for PMT computation rather than the default value of $2 \mathrm{~m} \mathrm{~s}^{-1}$ (scenario 3 ), though the regression still remains nonlinear, which can be related to the quality of the wind data; however it could not be appropriately analyzed as the wind is a local dependent variable, so having extreme spatial variability in this region.

In order to find a practical solution for improving the PMT estimates, it was supposed that using an appropriate regional wind speed instead of using a default value could improve the PMT estimation in windy areas (scenario 4); related results using an averaged seasonal wind speed are shown in Fig. 6s-x. In this scenario, two fixed wind speed values were used, respectively for cold and hot seasons. As shown in Fig. 6s-x, this approach was able to improve $R^{2}$ but did not provide improved regression coefficients since $b$ values indicate a quite large overestimation of $\mathrm{ET}_{0}$. Since all the observation datasets have different wind speeds, using the seasonal mean value improved some parts of the scatter plot but adversely impacted some other parts. Therefore, it can be concluded that since the wind speed is highly variable in time, it is likely that its time variation may have more influence than its magnitude in estimating PMT. In most of the stations the wind speed often is around $2 \mathrm{~ms}^{-1}$ throughout the year, whereas extreme winds may dominate a station only for specific periods of the year as is illustrated in Fig. 5; hence adopting any fixed value may lead to under- or over-estimation by the PMT method. As illustrated in Fig. $6 s-x$, using seasonal wind speed instead of the default value of $2 \mathrm{~m} \mathrm{~s}^{-1}$ is less successful in improving PMT results in windy stations and is therefore not advisable.

\subsection{Comparing PMT and HS methods}

As discussed earlier, the performances of both PMT and HS methods are generally adequate for estimating $\mathrm{ET}_{\mathrm{o}}$ for all climatic regions of Iran using limited available datasets. Table 6 presents the result of the Diebold and Mariano (1995) $B$ statistic test that was used for cross-comparison of the adequacy of the estimations by the two methods relative to the PM-ET ${ }_{0}$. The test value is out of the interval $[-1.96,1.96]$ when there is a significant difference at 95\% level. Results in Table 6 show that HS equation performed significantly better than PMT for 14 stations while PMT performed significantly better for 9 stations. It is worth noting that the statistic $B$ is positive (negative) and significant when HS (PMT) performed better. Better results for HS largely overcome those of PMT for the semi-arid region while PMT has shown to be superior for the humid and sub-humid areas. However, differences were not significant for $43 \%$ of stations considered in this study. Despite these statistic, the users should analyze the size of errors, particularly RMSE, the adequacy of linear regression, mainly relative to the value of 

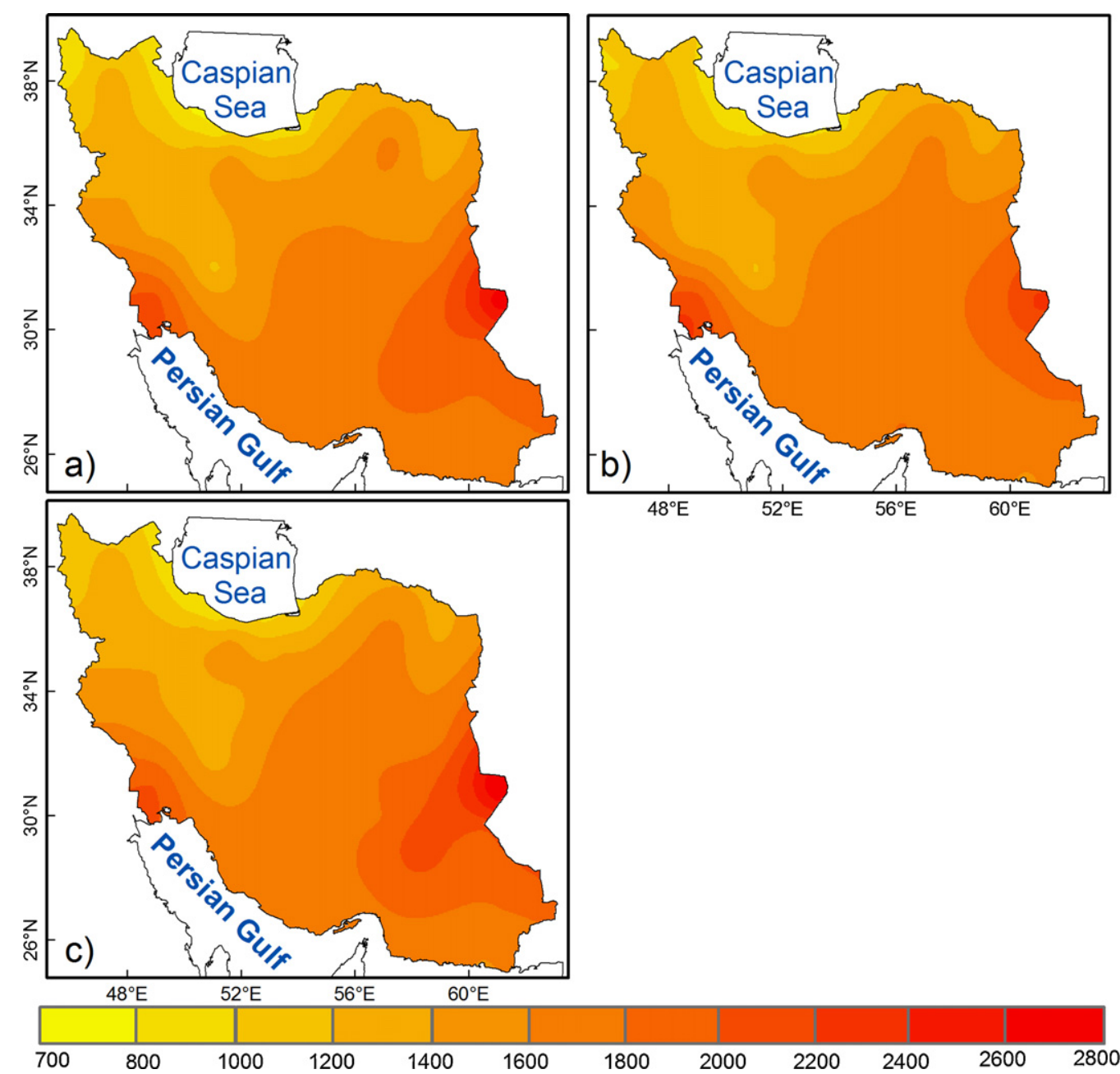

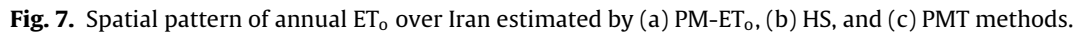

the regression coefficient $b$, as well as the efficiency indicators $\mathrm{EF}$ and $d_{\mathrm{IA}}$.

\subsection{Spatial pattern of $E T_{o}$}

The spatial pattern of annual $\mathrm{ET}_{\mathrm{o}}$ over Iran estimated with the $\mathrm{PM}-\mathrm{ET}_{\mathrm{O}}$ method using full datasets (Fig. 7a) shows a gradual increase of $\mathrm{ET}_{\mathrm{O}}$ from north to South, with the lowest values over the northern humid and sub-humid climates of Iran and larger $\mathrm{ET}_{0}$ estimates for arid and hyper-arid climates in the southern and eastern country. The range of annual $\mathrm{ET}_{\mathrm{o}}$ varies from $700 \mathrm{~mm}$ in the humid coastal areas of south-western Caspian Sea up to $2800 \mathrm{~mm}$ in hyper-arid desertic areas of eastern Iran. Most parts of the coastal areas of the Caspian Sea and the mountainous areas of northern and north-western Iran depict $\mathrm{ET}_{0}$ values between 700 and $1200 \mathrm{~mm}$, increasing southward and eastward due to the decrease in latitude and/or altitude. The mountainous areas of mid-western and north-eastern Iran, as well as the mid-central region of the country, exhibit $\mathrm{ET}_{\mathrm{o}}$ between 1200 and $1600 \mathrm{~mm}$, while the $\mathrm{ET}_{\mathrm{o}}$ values for a vast area in central, southern and eastern Iran range from 1600 to $2000 \mathrm{~mm}$. The highest $\mathrm{ET}_{\mathrm{o}}$ with $2000-2800 \mathrm{~mm}$ is observed in south-western and eastern Iran. The high $\mathrm{ET}_{\mathrm{o}}$ in south-western Iran is related to temperature, the highest observed in the country. Differently, in eastern Iran, it relates to the very high wind speed and dryness, with occurrence of very low annual mean relative humidity $(<40 \%)$ that even reduced to $<25 \%$ in summer when the region is exposed to extreme wind speed. The spatial pattern of PM-ET over Iran represented herein is comparable to that of for Dinpashoh (2006), though the number of used stations and the considered data periods are different. The obtained result is also consistent with the results achieved by Tabari et al. (2011a,b) and Tabari and Aghajanloo (2012) for eastern, western and northern Iran, respectively, considering both the magnitude and spatial variability of $\mathrm{ET}_{\mathrm{o}}$.

Fig. 7b and c shows the spatial patterns of $\mathrm{ET}_{\mathrm{o}}$ over Iran computed with the HS and PMT methods, respectively. These spatial

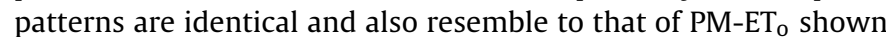
in Fig. 7a. However, Fig. 7b shows lower estimates of $\mathrm{ET}_{\mathrm{o}}$ for eastern Iran relative to Fig. 7a and c since it was not possible to use local wind speed for HS estimation contrarily to the case for PM and PMT methods. The observed concordance of HS and PMT maps (Fig. 7b and c) with the map of PM-ET (Fig. 7a), considering both the spatial pattern and the magnitude of the estimations, in addition to results in Tables 3 and 4, indicates that the HS and PMT methods are appropriate alternatives for estimation of $\mathrm{ET}_{0}$ in all climatic regions of Iran, particularly for the very remote areas, when only minimum and maximum temperature are available. Using PMT may be preferable when the dataset is partly comprising full data or partially full data because then it is possible to use the PMT for the periods when radiation or humidity data are required. Then the same FAO-PM equation is used with either observation or estimated data. Differently, the HS method is preferable if it is not desirable to correct $T_{\min }$ data to compensate for station aridity. 


\section{Discussion and conclusions}

Monthly averages of maximum and minimum temperature, relative humidity, sunshine duration and wind speed, corresponding to the period 1971-2005 at 40 Iranian synoptic stations distributed over the country were utilized for estimation of $\mathrm{ET}_{0}$ using the

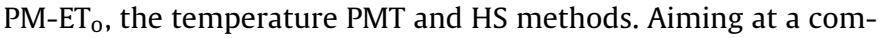
parative analysis of the behaviour of these methods, the climatic zones of Iran were identified utilizing the UNEP aridity index, which is based on the ratio of mean annual precipitation to mean annual potential evapotranspiration. To estimate $\mathrm{ET}_{\mathrm{o}}$ using both the HS and PMT methods, appropriate values for $k_{\mathrm{Rs}}$, an empirical radiation adjustment coefficient, were searched for each station. For estimation of $T_{\text {dew }}$ from $T_{\text {min }}$ to be used with the PMT, the latter was corrected for aridity. For humid climates an empirical approach to estimate $T_{\text {dew }}$ from the mean temperature was used and applied for PMT estimation. The performance of the HS and PMT methods against $\mathrm{PM}-\mathrm{ET}_{\mathrm{O}}$ were evaluated through a set of commonly used statistics.

Results show that searching appropriate $k_{\mathrm{Rs}}$ for estimation of solar radiation for both HS and PMT methods results in significant accuracy improvement in the estimation of $\mathrm{ET}_{\mathrm{O}}$. It was observed that $k_{\mathrm{Rs}}$ values for the stations located in the sub-humid and humid climates of western and northern Iran are smaller than those for the semi-arid to hyper-arid climates of central, southern and eastern Iran, suggesting a north-south and west-east increasing spatial trend. It was also found that the $k_{\mathrm{Rs}}$ values selected for both methods in a given station are either identical or show negligible difference. Despite results herein concern a wide range of climates, it is desirable to have these results confirmed through studies relative to other areas and using different time step computations.

The adjustment of $T_{\min }$ for estimating $T_{\mathrm{dew}}$ to be used with the PMT method has shown to highly improve the performance of the method for semi-arid to hyper-arid climates. Moreover, the adoption of an empirical approach to estimate $T_{\text {dew }}$ from the minimum temperature also significantly increased the accuracy of PMT estimation for humid climates. Overall, estimates by HS and PMT

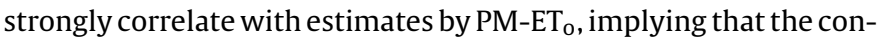
sidered methods appropriately predict $\mathrm{ET}_{\mathrm{o}}$ for all climatic regions of Iran if the appropriate $k_{\mathrm{Rs}}$ was considered. Results described also indicate that when datasets are incomplete, particularly relative to radiation and air humidity data, $\mathrm{ET}_{\mathrm{O}}$ calculations may be performed for the periods when data are lacking with the FAO-PM equation using radiation and/or VPD parameters estimated from $T_{\max }$ and $T_{\min }$ as for the PMT method.

The statistical test on differences between HS and PMT methods has shown that HS is more often significantly superior to PMT in the semi-arid region while the PMT performed significantly better than HS in humid and sub-humid areas. However, no significant differences were found for $43 \%$ of cases.

A weak/poor agreement was however found for some stations situated in the very dry climate of eastern and southern Iran owing to the role played there by extreme and variable wind speed. The observed discrepancies between HS (and PMT) and PM-ETo in the stations situated in eastern Iran is attributed to the extreme wind speed, particularly during summer when $\mathrm{ET}_{0}$ is higher. The observed disagreement between the estimations by PMT (and HS) and $\mathrm{PM}-\mathrm{ET}_{\mathrm{O}}$ may be partially due to not considering wind speed in HS method and to the less effective default wind speed value usually considered for PMT estimation, which is much lower than the

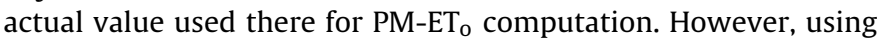
seasonal regional values as default wind speed values decreased the variance of residuals and the heteroscedasticity of regressions but increased the regression coefficients and therefore $\mathrm{ET}_{\mathrm{O}}$ became over-estimated in these hot and windy locations. It is likely that the time variability of wind speed plays a major role in the discrepancies between PMT and PM-ET $\mathrm{E}_{\mathrm{o}}$ estimates and therefore it is hardly possible to find a default value or empirical function that takes that variability into account in PMT when wind speed data are not available. Given these circumstances, it is likely not appropriate to try finding a modification of HS for considering wind speed. However, considering the need to minimize errors in estimating $\mathrm{ET}_{0}$ when only temperature data are available in areas where wind may play a major role, this problem remains open to further research developments.

The spatial distribution of annual $\mathrm{ET}_{\mathrm{o}}$ showed a gradual increasing from north to south, with the lowest $\mathrm{ET}_{0}$ values observed over northern humid and sub-humid climates of Iran and larger $\mathrm{ET}_{\mathrm{o}}$ estimates for arid and hyper-arid climates in the southern and eastern country. The spatial patterns of $\mathrm{ET}_{\mathrm{o}}$ computed using limited weather data with HS and PMT methods are identical and

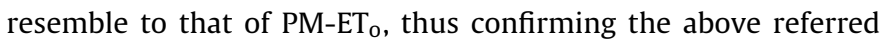
conclusions indicating that the HS and PMT methods are appropriate alternatives for estimation of $\mathrm{ET}_{\mathrm{o}}$ in all climatic regions of Iran, particularly for the very remote stations having only minimum and maximum temperature records.

\section{References}

Ahmadi, S.A., Fooladmand, H.R., 2008. Spatially distributed monthly reference evapotranspiration derived from the calibration of Thornthwaite equation: a case study, South of Iran. Irrigation Science 26, 303-312.

Allen, R.G., 1996. Assessing integrity of weather data for reference evapotranspiration estimation. Journal of Irrigation and Drainage Engineering 122 (2), 97-106.

Allen, R.G., 1997. Self-calibrating method for estimating solar radiation from air temperature. Journal of Hydrologic Engineering 2 (2), 56-67.

Allen, R.G., Smith, M., Perrier, A., Pereira, L.S., 1994. An update for the definition of reference evapotranspiration. ICID Bulletin 43 (2), 1-34.

Allen, R.G., Pereira, L.S., Raes, D., Smith, M., 1998. Crop Evapotranspiration. Guidelines for Computing Crop Water Requirements. FAO Irrig. Drain. Pap. 56. FAO, Rome, 300 p.

Allen, R.G., Pruitt, W.O., Wright, J.L., Howell, T.A., Ventura, F., Snyder, R., Itenfisu, D., Steduto, P., Berengena, J., Baselga, J., Smith, M., Pereira, L.S., Raes, D., Perrier, A., Alves, I., Walter, I., Elliott, R., 2006. A recommendation on standardized surface resistance for hourly calculation of reference $\mathrm{ET}_{0}$ by the FAO56 Penman-Monteith method. Agricultural Water Management 81, 1-22.

Allen, R.G., Pereira, L.S., Howell, T.A., Jensen, M.E., 2011. Evapotranspiration information reporting: I. Factors governing measurement accuracy. Agricultural Water Management 98 (6), 899-920.

Angström, A., 1924. Solar and terrestrial radiation. Quarterly Journal of the Royal Meteorological Society 50, 121-125.

Annandale, J.G., Jovanovic, N.Z., Benadé, N., Allen, R.G., 2002. Software for missing data error analysis of Penman-Monteith reference evapotranspiration. Irrigation Science 21, 57-67.

Berengena, J., Gavilán, P., 2005. Reference evapotranspiration estimation in a highly advective semiarid environment. Journal of Irrigation and Drainage Engineering 131 (2), 147-163.

Cai, J.B., Liu, Y., Lei, T.W., Pereira, L.S., 2007. Estimating reference evapotranspiration with the FAO Penman-Monteith equation using daily weather forecast messages. Agricultural and Forest Meteorology 145, 22-35.

Cai, J., Liu, Y., Xu, D., Paredes, P., Pereira, L.S., 2009. Simulation of the soil water balance of wheat using daily weather forecast messages to estimate the reference evapotranspiration. Hydrology and Earth System Sciences 13, 1045-1059.

Diebold, F.X., Mariano, R.S., 1995. Comparing predictive accuracy. Journal of Business and Economic Statistics 13, 253-263.

Dinpashoh, Y., 2006. Study of reference crop evapotranspiration in I.R. of Iran. Agricultural Water Management 84, 123-129.

Dinpashoh, Y., Fakheri-Fard, A., Mogaddam, M., Jahanbakhsh, S., Mirnia, M., 2004. Selection of variables for the purpose of regionalization of Iran's precipitation climate using multivariate methods. Journal of Hydrology 297, 109-123.

Dinpashoh, Y., Jhajharia, D., Fakheri-Fard, A., Singh, V.P., Kahya, E., 2011. Trends in reference evapotranspiration over Iran. Journal of Hydrology 399, 422-433.

Diodato, N., Bellocchi, G., 2007. Modeling reference evapotranspiration over complex terrains from minimum climatological data. Water Resources Research 43, W05444, http://dx.doi.org/10.1029/2006WR005405.

Droogers, P., Allen, R.G., 2002. Estimating reference evapotranspiration under inaccurate data conditions. Irrigation and Drainage Systems 16, 33-45.

Fooladmand, H.R., Haghighat, M., 2007. Spatial and temporal calibration of Hargreaves equation for calculating monthly $\mathrm{ET}_{\mathrm{o}}$ based on Penman-Monteith method. Irrigation and Drainage 56, 439-449.

Fooladmand, H.R., Zandilak, H., Ravanan, M.H., 2008. Comparison of different types of Hargreaves equation for estimating monthly evapotranspiration in the south of Iran. Archives of Agronomy and Soil Science 54 (3), 321-330. 
Gavilán, P., Berengena, J., Allen, R.G., 2007. Measuring versus estimating net radiation and soil heat flux: impact on Penman-Monteith reference ET estimates in semiarid regions. Agricultural Water Management 89, 275-286.

Gocic, M., Trajkovic, S., 2010. Software for estimating reference evapotranspiration using limited weather data. Computers and Electronics in Agriculture 71, $158-162$.

Gong, L., Xu, C.Y., Chen, D., Halldin Sven Chen, Y.D., 2006. Sensitivity of the Penman-Monteith reference evapotranspiration to key climatic variables in the Changjiang (Yangtze River) basin. Journal of Hydrology 329, 620-629.

Hargreaves, G.H., 1994. Defining and using reference evapotranspiration. Journal of Irrigation and Drainage Engineering 120 (6), 1132-1139.

Hargreaves, G.H., Allen, R.G., 2003. History and evaluation of Hargreaves evapotranspiration equation. Journal of Irrigation and Drainage Engineering 129 (1), 53-63.

Hargreaves, G.H., Samani, Z.A., 1982. Estimating potential evapotranspiration. Journal of the Irrigation and Drainage Division 108 (3), 225-230.

Hargreaves, G.H., Samani, Z.A., 1985. Reference crop evapotranspiration from temperature. Applied Engineering in Agriculture 1 (2), 96-99.

Jabloun, M., Sahli, A., 2008. Evaluation of FAO-56 methodology for estimating reference evapotranspiration using limited climatic data application to Tunisia. Agricultural Water Management 95, 707-715.

Jensen, M.E., Burman, R.D., Allen, R.G., 1990. Evapotranspiration and Irrigation Water Requirements. ASCE Manuals and Reports on Engineering Practices No. 70. American Society of Civil Engineers, New York, NY, p. 360.

Jensen, D.T., Hargreaves, G.H., Temesgen, B., Allen, R.G., 1997. Computation of ET $_{0}$ under nonideal conditions. Journal of Irrigation and Drainage Engineering 123 (5), 394-400.

Kra, E.Y., 2010. An empirical simplification of the temperature Penman-Monteith model for the tropics. Journal of Agricultural Science 2 (1), 162-171.

Lawrence, M.G., 2005. The relationship between relative humidity and the dewpoint temperature in moist air. A simple conversion and applications. Bulletin of the American Meteorological Society, http://dx.doi.org/10.1175/BAMS-86-2-225.

Liu, Y., Pereira, L.S., 2001. Calculation methods for reference evapotranspiration with limited weather data. Journa of Hydraulics 3, 11-17 (in Chinese).

López-Moreno, J.I., Hess, T.M., White, S.M., 2009. Estimation of reference evapotranspiration in a mountainous Mediterranean site using the Penman-Monteith equation with limited meteorological data. Pirineos 164, 7-31.

Martí, P., Zarzo, M., 2012. Multivariate statistical monitoring of $\mathrm{ET}_{0}$ : a new approach for estimation in nearby locations using geographical inputs. Agricultural and Forest Meteorology 152, 125-134.

Martinez, C.J., Thepadia, M., 2010. Estimating reference evapotranspiration with minimum data in Florida. Journal of Irrigation and Drainage Engineering 136 (7), 494-501.

Modarres, M., Ouarda, T.B.M.J., 2012. Generalized autoregressive conditional heteroscedasticity modelling of hydrologic time series. Hydrological Processes, http://dx.doi.org/10.1002/hyp.9452.

Mohammadi, H., Su, L., 2010. International evidence on crude oil price dynamics: applications of ARIMA-GARCH models. Energy Economics 32, 1001-1008.

Moriasi, D.N., Arnold, J.G., Van Liew, M.W., Bingner, R.L., Harmel, R.D., Veith, T.L., 2007. Model evaluation guidelines for systematic quantification of accuracy in watershed simulations. Transactions on ASABE 50 (3), 885-900.

Nandagiri, L., Kovoor, G.M., 2005. Sensitivity of the food and agriculture organization Penman-Monteith evapotranspiration estimates to alternative procedures for estimation of parameters. Journal of Irrigation and Drainage Engineering 131 (3), 238-248.

Nandagiri, L., Kovoor, G.M., 2006. Performance evaluation of reference evapotranspiration equations across a range of Indian climates. Journal of Irrigation and Drainage Engineering 132 (3), 238-249.

Nash, J.E., Sutcliffe, J.V., 1970. River flow forecasting through conceptual models: Part 1. A discussion of principles. Journal of Hydrology 10 (3), 282-290.

Paredes, P., Rodrigues, G.C., 2010. Necessidades de água para a rega de milho em Portugal Continental considerando condições de seca. In: Pereira, L.S., Mexia, J.T.,
Pires, CA.L. (Eds.), Gestão do Risco em Secas. Métodos. Tecnologias e Desafios. Edições Colibri e CEER, Lisboa, pp. 301-320.

Paulo, A.A., Rosa, R., Pereira, L.S., 2012. Climate trends and drought indices based on precipitation and evapotranspiration in Portugal. Natural Hazards and Earth System Sciences 12, 1481-1491.

Pereira, L.S., Perrier, A., Allen, R.G., Alves, I., 1999. Evapotranspiration: review of concepts and future trends. Journal of Irrigation and Drainage Engineering 125 (2), 45-51.

Pereira, L.S., Cai, L.G., Hann, M.J., 2003. Farm water and soil management for improved water use in the North China Plain. Irrigation and Drainage 52 (4) 299-317.

Popova, Z., Kercheva, M., Pereira, L.S., 2006. Validation of the FAO methodology for computing $\mathrm{ET}_{\mathrm{o}}$ with missing climatic data. Application to South Bulgaria. Irrigation and Drainage 55 (2), 201-215.

Rahimikhoob, A., 2010. Estimation of evapotranspiration based on only air temperature data using artificial neural networks for a subtropical climate in Iran. Theoretical and Applied Climatology 101, 83-91.

Raziei, T., Bordi, I., Pereira, L.S., 2008. A precipitation-based regionalization for Western Iran and regional drought variability. Hydrology and Earth System Sciences $12,1309-1321$

Samani, Z., 2000. Estimating solar radiation and evapotranspiration using minimum climatological data. Journal of Irrigation and Drainage Engineering 126 265-267.

Samani, Z., 2004. Discussion of "History and evaluation of Hargreaves evapotranspiration equation" by George H. Hargreaves and Richard G. Allen. Journal of Irrigation and Drainage Engineering ASCE 130 (5), 447-448.

Smith, M., 2000. The application of climatic data for planning and management of sustainable rainfed and irrigated crop production. Agricultural and Forest Meteorology 103, 99-108.

Tabari, H., 2010. Evaluation of reference crop evapotranspiration equations in various climates. Water Resources Management 24 (10), 2311-2337.

Tabari, H., Aghajanloo, M.B., 2012. Temporal pattern of aridity index in Iran with considering precipitation and evapotranspiration trends. International Journal of Climatology, http://dx.doi.org/10.1002/joc.3432.

Tabari, H., Aeini, A., Hosseinzadeh Talaee, P., Shifteh Some'e, B., 2011a. Spatial distribution and temporal variation of reference evapotranspiration in arid and semiarid regions of Iran. Hydrological Processes, http://dx.doi.org/10.1002/hyp.8146

Tabari, H., Marofi, S., Aeini, A., Hosseinzadeh Talaee, P., Mohammadi, K., 2011b. Trend analysis of reference evapotranspiration in the western half of Iran. Agricultural and Forest Meteorology 151, 128-136.

Temesgen, B., Allen, R.G., Jensen, D.T., 1999. Adjusting temperature parameters to reflect well-watered conditions. Journal of Irrigation and Drainage Engineering 125 (1), 26-33.

Temesgen, B., Eching, S., Davidoff, B., Frame, K., 2005. Comparison of some reference evapotranspiration equations for California. Journal of Irrigation and Drainage Engineering 131 (1), 73-84

Thornthwaite, C.W., 1948. An approach toward a rational classification of climate. Geographical Review 38 (1), 55-94.

Todorovic, M., Karic, B., Pereira, L.S., 2013. Reference evapotranspiration estimate with limited weather data across a range of Mediterranean climates. Journal of Hydrology, http://dx.doi.org/10.1016/j.jhydrol.2012.12.034.

Trajkovic, S., 2005. Temperature-based approaches for estimating reference evapotranspiration. Journal of Irrigation and Drainage Engineering 131 (4), 316-323.

Trajkovic, S., 2007. Hargreaves versus Penman-Monteith under humid conditions Journal of Irrigation and Drainage Engineering 133 (1), 38-42.

Trajkovic, S., Kolakovic, S., 2009. Evaluation of reference evapotranspiration equations under humid conditions. Water Resources Management 23, 3057-3067.

UNEP, 1997. World Atlas of Desertification, 2nd ed. United Nations Environment Programme, Arnold, London, p. 182.

Willmott, C.J., 1981. On the validation of models. Physical Geography 2, 184-194. 